\title{
A QUALITATIVE STUDY OF STROKE SURVIVORS' EXPERIENCE OF SENSORY CHANGES
}

\author{
By \\ (C) 2018 \\ Dua'a Akram Alwawi \\ MSOT, Saginaw Valley State University, 2014 \\ B.Sc., University of Jordan, 2011 \\ Submitted to the graduate degree program in Therapeutic Science and the Graduate Faculty of \\ the University of Kansas in partial fulfillment of the requirements for the degree of Doctor of \\ Philosophy. \\ Evan Dean, PhD, OTR/L (Co-Chair) \\ Lisa Mische-Lawson, PhD, CTRS (Co-Chair) \\ Winnie Dunn, PhD, OTR, FAOTA \\ Jill Peltzer, PhD, APRN-CNS \\ Mindy Bridges, PhD, CCC-SLP
}

Date Defended: 7 August 2018 
The Dissertation Committee for Dua'a Akram Alwawi certifies that this is the approved version of the following dissertation:

\section{A QUALITATIVE STUDY OF STROKE SURVIVORS' EXPERIENCE OF SENSORY CHANGES}

Evan Dean, PhD, OTR/L (Co-Chair)

Lisa Mische-Lawson, PhD, CTRS (Co-Chair)

Date Approved: 7 August 2018 


\begin{abstract}
Background. Previous literature examined tactile and proprioceptive changes after stroke; however, the lived experience of changes in all sensory systems is still a gap in the literature. Purpose. To gain understanding of stroke survivors' experience of sensory changes and how sensory changes impact participation in daily life activities. Method. This study utilized a qualitative description method. Researchers used semi-structured interviews with probing questions. Inductive content analysis approach was used to analyze the data. Researchers recruited thirteen stroke survivors $\leq 75$ years old who participated in a community program. Findings. Emerging themes included Daily Life Impact of Sensory Function Changes, and Experience and Timing of Sensory Changes. Participants experienced changes in various sensory systems including touch and proprioception, visual, auditory, and taste. Survivors also reported sensitivity to environmental stimuli. Sensory changes affect survivors' participation in daily life. Implications. Results from this study inform health care providers about stroke survivors' sensory needs to help them design interventions that match their needs.
\end{abstract}

Keywords: Sensation, Occupational therapy, Sensory processing, Participation, Stroke 


\section{Acknowledgments}

"My Lord, enable me to be grateful for Your favor which You have bestowed upon me and upon my parents and to do righteousness of which You approve” (Qur'an 27-19)

I would like first to give my highest gratitude to Dr. Evan Dean, my mentor and co-chair, and Dr. Winnie Dunn, my other research mentor and dissertation committee member. Dr. Dean, thank you for your guidance, patience, encouragements, and support you provided me through all stages of my dissertation and comprehensive exams. From your wide and immense background, you helped me to view data from multiple perspectives. You always had great suggestions for resources to accomplish the dissertation process in a timely manner. Your support and mentorship helped me to develop as a researcher. I am grateful and proud to have a great mentor. I also owe a debt of gratitude to Dr. Winnie Dunn for all the time, support, encouragement, guidance you provided throughout these four years. Dr. Dunn, I would not be the innovative researcher I am today if it was not for you. You always challenged me to think out of the box, question assumptions, and view issues from multiple perspectives. Thank you for believing in me and encouraging me to continue the path I chose in my research. You always mentioned the importance of appreciating the lived experience of people which showed me my passion in this type of research.

I am deeply grateful for the expertise of my dissertation committee members. I am especially thankful to Dr. Lisa Mische-Lawson for being willing to assist as a co-chair for my dissertation. I am also thankful for her support, guidance, and encouragement through the dissertation process and the second comprehensive exam. Dr. Mische-Lawson, you always provided me with the most insightful, thorough, and detail-oriented comments which had a huge impact on the quality of the dissertation. I have benefited greatly from your expertise and 
enormous knowledge in qualitative research. I am very grateful to your words of encouragement and positivity which provided me with confidence and motivation through my entire program.

I want also to extend my greatest acknowledgment to Dr. Jill Peltzer for her encouragement, quick and thoughtful feedback. Throughout the process, you always found the time to meet, and shared your experience and resources to assist in my learning about qualitative research and data analysis. Your lovely meetings and words of encouragement had a huge impact on the quality of my research. I would also like to thank Dr. Mindy Bridges for the help she provided in writing the method section. Your thoughtful and detail-oriented feedback helped me to be aware of choosing the words I use in my writing, so it is easier to understand by people from different discipline.

I am particularly thankful to the occupational therapy masters' students for their help in collecting and analyzing the project's data. I would especially like to thank Ashleigh Heldstab for her hard work, enthusiasm and motivation in collecting and analyzing the data, and her help in organizing of the results section. My appreciation is also extended to all study participants for making this study possible. I appreciate your willingness to share your experiences and stories with me. I also acknowledge the help and guidance provided by the staff of American Stroke Foundation which facilitate data collection and recruitment.

I am also grateful for my friends who provided me with tremendous help and support throughout this journey. I want particularly to thank my best friend Ekhlas for being there whenever I needed help and support. Thank you for your true friendship, words of encouragement and for your help in taking care of Qutaibah when I needed it to get my writing done. I never needed to ask for help from you. Your friendship is invaluable. I also would like to extend my acknowledgments to my friends Nisreen and Nadia for their help in revising the 
dissertation document and providing quick feedback. This document has fewer grammatical errors because of your help.

Finally, and most importantly I want to send my greatest appreciation and acknowledgment to my family abroad, husband and son to whom this work is dedicated. This journey haven not been possible without the unlimited support and love provided by them, I have been very blessed with having them all in my life. Dad (Akram Alwawi) and Mom (Asma'a Afleifel), thank you for being great role models to me. It is an honor to be your daughter. I would not have been the person I am today if it was not for you. You have always stressed the importance of education and science which made me unconsciously value and love continuing my graduate studies. I want to say thank you for being brave and giving me the opportunity to follow my dream and travel overseas to be where I am today (although I know after I became a mom that this was a very hard decision to make). You have raised me to work around obstacles and be brave to face challenges to achieve my goal. Even though we are thousands of miles apart, your untiring support, love, prayers, encouragement and inspiration was the fuel to give me the strength and achieve the goal that we are all have dreamt about. Thank you for believing in me. Thank you for listening to me talking about my studying abroad over and over without showing any signs of boredom, and you didn't stop offering advice and help me making decisions even when it was just days before the defense. You have always supported me when I went through difficult times. I cannot thank you enough for what you have done to help me reach this point of my life.

I also want to extend my appreciation to my sisters Feda, Shefa'a, Noor, Ala'a, Mona, Batool, and little Joud, for their constant support, love, and prayers. You always sent words of encouragement and added a humor to my life which gave me the strength and motivation when I 
went through difficult times. Thank you for listening and offering me advice over these years. You always were and will be my best friends. I am also especially thankful to Feda for her support in the last month of my dissertation work in taking care of Qutaibah when needed to get my writing done. My parents and my sisters, I know my achievement is yours, so I hope that I have made you all proud. My words cannot express my love and appreciation for what you have done to me throughout this process. I love you all so much, and I dedicate this work to you.

My sincere appreciation is extended to the two men of my life; my husband (Ahmad Bakeer), and my son (Qutaibah). You both are the best thing that happened to me over the last four years. To the world's best husband, Ahmad, you are the gift that came to my life at the beginning of my journey of studying to be my family when I was away from my family, and to give me the courage I needed to overcome challenges. There is no way to express my love and appreciation for your ongoing love, support, patience, and understanding. Thank you for helping me balance between my graduate work, home responsibilities, and taking care of Qutaibah. I could not have done this without you. You always believed in me and provided me with confidence that I can do anything regardless how difficult it was. We have certainly shared our ups and downs together over the last four years, and you have been always there whenever I needed you even in your difficult times. Thank you for being patient with me when I am frustrated, thanks for listening to my problems and providing perspective, thanks for celebrating with me when I achieve little things. Thanks for listening to me when I practiced my presentation more than one time and providing feedback without showing boredom. The flowers you always brought to cheer me up were more valuable than you realize. I love you now and forever. 
My final appreciation is extended to the light of my life, my little boy, Qutaibah. You came to our life unexpectedly and brought all the joy, happiness, and love. I cannot tell you how much I love you. As my responsibility increased when I have had you, I was afraid that I will not be able to finish my study in a timely manner. However, your innocent smile has been the strongest motivation and determination for me to succeed. You behaved as the most patient baby ever and made it possible for me to continue what I have started. Thank you for your understanding on spending so much time in front of the laptop writing instead of playing with you. When you grow enough to read this dissertation, I hope you will understand why I spent the time carrying you with one hand and typing with the other, and then I hope you will appreciate the importance of education and you will be proud of me. I cannot say that it was easy to have graduate studies and baby at the same time, but you made the difficulty of the study bearable. You are the gift from Allah that I didn't know I need in this journey until I had you. Thank you for being the relief from many intervals of anxiety, loneliness, and depression. I hope I have been a good mom and I didn't lose much during the journey of studying. I love you from the bottom of my heart, and I dedicate this work to you.

"Praise to Allah, who has guided us to this; and we would never have been guided if Allah had not guided us." (Qur'an 7-43) 


\section{Table of Contents}

$\begin{array}{ll}\text { Introduction } & 1\end{array}$

$\begin{array}{ll}\text { Methods } & 2\end{array}$

$\begin{array}{lr}\text { Findings } & 8\end{array}$

$\begin{array}{ll}\text { Discussion } & 15\end{array}$

$\begin{array}{ll}\text { Conclusion } & 19\end{array}$

$\begin{array}{ll}\text { Tables } & 21\end{array}$

$\begin{array}{ll}\text { References } & 24\end{array}$

Appendices

Appendix A: Student Training $\quad 32$

Appendix B: Comprehensive Examination One $\quad 34$

Appendix C: Comprehensive Examination Two 59

$\begin{array}{ll}\text { Appendix D: Comprehensive Examination Three } & 85\end{array}$ 


\section{Introduction}

People experience life through their senses. Sensations are important to interact safely with the environment and participate in daily life activities (Tyson et al., 2008; Rhoda, 2012). Sensory changes are common after stroke, which can influence participation in daily life activities (Connell, 2008; Doyle, Bennett, \& Dudgeon, 2014; Connell, McMahon, \& Adams, 2014). For example, motor recovery is highly dependent on sensory function, and therapy targeting motor control needs to include sensory components to achieve better outcomes (Bolognini, Russo, \& Edwards, 2016). However, health professionals and researchers neglect the sensory aspects of the rehabilitation process, as these changes are less apparent than motor and cognitive changes (Doyle et al., 2014).

The majority of the literature available regarding sensory changes after stroke focuses on highlighting somatic sensation changes (i.e., touch, proprioception, temperature, and pain; Bolognini et al., 2016). Evidence describing the lived experiences of somatosensory system changes is also available, but there is currently limited research focusing on the lived experiences of changes in stroke survivors' other sensory systems such as vision, taste, and smell.

Depending on the area or the size of the brain affected, different sensory systems could be changed by stroke (Grefkes \& Fink, 2011). Landi (2006) indicated that $86 \%$ of stroke survivors demonstrated hearing changes that were not identified by neurologists or health care professionals. Other researchers have found that reduced taste sensation and intra oral sensitivity among stroke survivors impacted meal time experience after stroke (Jacobsson, Axelsson, Wenngren, \& Norberg, 1996; Schimmel, Voegeli, Duvernay, Leemann, and Muller, 2017). Moreover, survivors reported sensitivity to environmental stimuli after stroke (Carlsson, 
Moller \& Blomstrand, 2009). Despite the frequency of reporting sensitivity to sensory stimuli such as light and sound, researchers have not explored this area in the literature.

The lived experience of sensory changes among community-dwelling stroke survivors is a current gap in the research. This study seeks to fill the gap by answering two questions:

1. What sensory changes did individuals experience after a stroke?

2. How did sensory changes affect meaningful activities?

\section{Methods}

To answer the research questions above, researchers used a qualitative method. A qualitative method is appropriate to use when there is little known about the problem (Patton, 2002). There is little research studying the experience of sensory changes among stroke survivors; therefore, conducting a qualitative approach was appropriate for the current study. Researchers used the Consolidated Criteria for Reporting Qualitative Research (COREQ; a 32item checklist) guidelines to establish detailed transparent methods to report our findings (Tong, Siansbury, \& Craig, 2007).

\section{Design}

This study utilized a qualitative description design to gain understanding of stroke survivors' experience of sensory changes and how sensory changes impact participation in daily life activities. With qualitative description design, researchers seek to understand the participants' experiences and perspectives regarding specific phenomenon from their viewpoint without having predetermined variables or theoretical assumptions (Lincoln and Guba, 1985; Sandelowski, 2000).

Qualitative description is a method of naturalistic inquiry that aims to describe a group of peoples' experiences or events using their own words (Sandelowski, 2000). Naturalistic inquiry 
was proposed by Lincoln and Guba (1985) as a paradigm to understand real-world situations.

Researchers use naturalistic inquiry as a qualitative method to understand individuals' experiences in their natural setting. The design is useful in nursing and health science research because it provides clear information on how to improve practice (Sandelowski, 2000; SullivanBolyai, Bova, and Harper, 2005). Additionally, insights developed from qualitative description tend to be readily applicable to practitioners, leading to quicker adoption in clinical settings (Sandelowski, 2000, 2010).

\section{Participants}

Researchers used purposive sampling to recruit participants who experienced sensory changes after stroke from an established community program. Researchers asked potential participants if they experienced sensory changes after stroke and if daily life was affected due to these changes. Researchers confirmed participant met inclusion criteria with program records.

Potential participants were both males and females younger than 75 years old. To ensure capacity to respond to the interview questions, researchers included participants who scored 26 or higher on the Montreal Cognitive Assessment based on their medical records (MoCA; Chiti and Pantoni, 2014). Researchers excluded participants who had a receptive or expressive aphasia, dementia, and/or central nervous system diseases other than stroke (e.g., traumatic brain injury). According to Pohl et al. (2003) people older than 75 years of age experience noticeable sensory processing changes due to the aging process. Therefore, researchers included people younger than 75 years old, so the sensory changes reported by participants were likely attributed to the stroke rather than the aging process. Survivors were one to seven years past their post-stroke and participated in a community setting in an urban 
Midwestern city of approximately 160,000 people (U.S. Census, 2017). According to findings of our previous research ("redacted for review"), participants reported they began noticing sensory changes one-two years after their stroke. Though people may experience immediate sensory changes after stroke, they may need time and perspective to notice sensory changes due to the many other changes caused by stroke (i.e. physical, participation, cognitive).

Based on previous literature, researchers expected to reach saturation by recruiting fivetwelve participants. Researchers recruited participants until they reached saturation in the study research questions - that is, when new participants offered no new insights (Sandelowski, 2008). Saturation of data emerged within nine interviews, which is consistent with previous literature (Guest, Bunce, Johnson, 2006; Connell et al., 2014). To ensure we reached saturation, four additional interviews were conducted. To obtain the sample, researchers contacted seventeen participants and four participants were excluded as they did not experience sensory changes after stroke.

\section{Data Collection}

Individual semi-structured interview. Researchers developed open-ended questions with probes to facilitate the interview. Experts in sensory processing reviewed the prepared questions and provided suggestions and feedback. Questions asked the participants about the impact of sensory changes on their involvement in daily activities, and the impact of the environment on their participation. The team piloted the interview questions with three participants to determine feasibility. The questions were modified based on the pilot study. The final version of the questions is listed in Table 1. The three pilot participants were reinterviewed using the finalized questions, thus they are included in the final sample. Researchers also used a separate demographic form to collect demographic information and 
stroke-related information (e.g., stroke onset, side of stroke, and type of stroke) at the start of the interview.

Procedure. After receiving university Institutional Review Board approval, researchers posted flyers at a community-based stroke program. Additionally, researchers contacted the director of the program to help to identify people who may be willing to participate. When potential participants expressed willingness to participate in the study, researchers asked them if they had experienced sensory changes after stroke to be sure they were a match for the study. After a participant consented to be a part of the study, researchers reviewed the participant's record to determine if he/she fit the inclusion and exclusion criteria. Then participants completed the demographic survey and participated in the semi-structured interview which took approximately 45 minutes. The interview started with broad questions and followed with more detailed questions for clarification. Data collection occurred from March 2018 to May 2018.

The research team consisted of the first author and four Masters' of Occupational Therapy (MOT) students in their final semester. The first author is an expert in sensory processing and community rehabilitation for people with stroke. The first author and one student conducted and transcribed interviews (following the protocol described below). All researchers, including the student who helped with data collection, then completed data analysis.

Student training. The lead researcher followed the 5-phase protocol training for interviewer and coder suggested by Goodell, Stage, and Cooke (2016). See Appendix A for more details on conducting the training. Reliability between coders is described in the analysis section.

\section{Data Analysis}

Researchers used an inductive content analysis approach to explore the stroke survivors' experience of sensory changes, and its impact on participation. Inductive content analysis is an 
approach to qualitative data analysis that is used when there is little known about a particular phenomenon (Elo \& Kyngas, 2008). The interviews were recorded and transcribed verbatim. Each researcher transcribed the interviews that she collected to maximize immersion in the data. Transcribing one's own data is important step to achieve accuracy in data analysis; since the researcher understands the words within its context due to familiarity with the interview (MacLean, Meyer, \& Estable, 2004; Bailey, 2008). All researchers confirmed that the interviews were transcribed accurately by listening to the recorded interviews while reading the written transcripts.

The data collection and data analysis started simultaneously; researchers began data analysis immediately following the completion of the first interview and proceeded until all data were analyzed. Therefore, data collection and data analysis mutually shape each other, as Sandelowski (2000) stated, "In qualitative content analysis, the researcher continuously modifies their treatment of data to accommodate new data and new insights of those data" (p. 338).

Researchers used the coding process adapted from Graneheim and Lundman (2004). The coders used an iterative process to develop codes and themes. The coders began by reading interview transcripts independently several times to identify meaning units. They then identified their own set of codes by condensing meaning units into codes. As the team went through the coding process, they compared codes that emerged from the new transcripts to the codes already defined. Researchers combined similar codes into categories, then they defined each category to be used in the coding process for future coding. They then created a coding dictionary where they added codes, category definitions, and examples. The research team met regularly to discuss areas of confusion with the definitions and revised the categories' definition accordingly. The research team reached consensus for all categories. Researchers 
used the revised coding dictionary to complete coding the new transcripts, then repeated this process as new transcripts were added.

To establish the reliability of data analysis, six (46\%) of the transcripts were coded by at least two researchers. Transcripts were coded simultaneously by more than one researcher at different points throughout the study (i.e., team coding). Researchers did two rounds of team coding to establish reliability and reach $80 \%$ of agreement . First, they used the first version of the coding dictionary to achieve $75 \%$ of agreement. Any inconsistency between researchers on the codes or categories was discussed as a team to improve the clarity of categories' definitions. For the second round of reliability coding, the researchers added examples and modified the definitions of the categories for clarity. The research team then used the updated coding dictionary to reach a final agreement level of $89.6 \%$. To further confirm reliability, at the end of data analysis, two researchers completed a third and final reliability check on the newly collected transcripts and reached consensus for the codes and categories. After researchers determined the reliability of the categories, they grouped similar categories into overarching themes. Once researchers put the coding process in place, the primary author consulted with two senior qualitative researchers to ensure the accuracy of the analysis process.

Trustworthiness and Methodological Rigor. Trustworthiness is established in qualitative research by addressing five tenets as described by Guba and Lincoln (1985): (1) credibility, (2) transferability, (3) dependability, (4) confirmability, and (5) authenticity.

Researchers utilized reflective journaling before, during and after interviews; peer debriefing during data collection and analysis, and field notes to assist establishing credibility. Member checking was also used during and after each interview; interviewers recapped the thoughts and ideas shared by participants and gave them the chance to further clarify their 
points. The research team met several times to create and refine codes and categories to maintain dependability. The primary author also consulted two senior qualitative researchers to enhance credibility and dependability of the analysis process. To support confirmability, researchers completed coding independently and met collectively to discuss their own codes and categories until they reached consensus. They also conducted team coding on six transcripts to ensure consistency between coders to further support confirmability.

Researchers supported the transferability of the study findings through a detailed description of the procedure, field notes, and accurately transcribed interviews. Additionally, a rich description of participant experiences is provided to support transferability. The team created an audit trail of meeting minutes and coding decisions to further support transferability by noting the research process and changes throughout the study. They used the audit trail to reflect on decisions made and consider coding decisions related to the researchers' inherent biases. The audit trail is a crucial piece of academic rigor needed for qualitative studies.

\section{Findings}

Researchers interviewed thirteen stroke survivors ( $M=64.38, S D=6.7$ years), eight males and five females (see Table 2 for description of the sample). Two major themes emerged from data analysis, which provide insight about the experience and impact of sensory changes experienced after stroke (see Table 3). The two themes included Daily Life Impact of Sensory Function Changes, and Experience and Timing of Sensory Changes.

\section{Daily Life Impact of Sensory Function Changes}

This theme describes participants' every-day experiences of sensory changes after stroke. Researchers organized these functions according to the "Occupational Therapy Practice Framework: Domain and Process" (American Occupational Therapy Association [AOTA], 
2017), which include visual, hearing, taste, smell, touch, multisensory changes, and sensitivity to pressure and temperature.

Vision changes. Participants experienced many different types of changes in their vision that affected their participation in daily activities. A common change was increased sensitivity to light. Participant 6 shared "for some reason the light does bother me more." He expanded more on how sensitivity to light affected the completion of his work's tasks 'I'd rather done this interview in the dark. When I came in in the morning, I set everything up I do it in the dark.”

Participant 9, who was active in the community before stroke, noted leaving the house was more difficult because sunlight was the most noxious stimuli, "fluorescents didn't bother me, but sunlight was really bad. It really bothered my eyes a lot... I don't want to go outside as much because the sun.” Another change that participants experienced was a visual field loss. Participant 2 shared how visual loss impacted his life "My peripheral vision, my left side, about $10 \%$ of it has been eliminated, so I bump into things and I bump into people.”

Hearing changes. Several participants reported changes in sensory function related to hearing. The most salient change discussed was experiencing increased sensitivity to the noises around them. Participant 5 described how she felt uncomfortable at her church, a previously preferred activity, due to the noise "there is still so much activity and up and down and noise level and everything I am just not comfortable with that." The same participant compared her ability to attend quiet activities to crowded activities, she shared:

I mean we go to the movies occasionally but that doesn't bother me because it is quiet, but in our social, and even our church is sometimes stressful to go to, and I am always thinking it should be a nice time to be peaceful and meditating. 
Participant 3 noticed the sensitivity to noise as an increased startle reflex "when I hear a big bang I jump more now, and I didn't use to do that." Participant 9 described the increased sensitivity as a heightened awareness of sounds while eating, "I can't stand a fork across a plate."

Heightened taste. Some participants experienced changes in the taste of a variety of food, and one of them experienced loss of taste. Participant 10 described a temporary loss of taste as being "numb" but noted that with time "my taste got better." Most participants described an increase in the sensitivity to taste. Participant 11 described the sensitivity as "some of the spices are more potent after the stroke." In some instances, this improved the flavor of some types of food, as Participant 9 shared "I could really taste sweets." In most cases, however, participants described the increased sensitivity as a reason for no longer enjoying certain flavors of foods. Participant 2 described a spicy flavor that had increased in sensitivity, "jalapenos bother me. They used to not at all but now they do."

Smell intolerance and sensitivity. Two participants described a similar experience of an increased in sensitivity to smell, both related to food. Participant 11 described his loss of interest in eating some food his wife uses to cook that he used to love due to decreased tolerance to smell of spices:

I've always loved her food but now some of the spices she uses, I have to tell her not to use them. It just makes the food not smell good no more ... if it don't smell good, even though I know it taste good, still to me it don't.

Additionally, Participant 9 shared similar experiences with sensitivity to the smell of certain foods, "right after the stroke just the smell of the spice made me almost nauseous." She also described not being able to eat her favorite food after the stroke because of the smell, "that was one thing I really noticed though because I used to love Chinese food." 
Altered touch and proprioception. Touch sensations were another area many participants described as having changed after a stroke. Common experiences reported were both tingling and numbness in upper and lower extremities; "I did have numbness on the right side" (Participant 13). However, the unique experience was what Participant 10 described of the feeling inside of and around his mouth by alluding to the feeling of Novocain, he said:

for my lip down to my chin, this side was numb...So now it's just the tip on the right side, it's more like, you've gone to the dentist and they gave you Novocain to work on a tooth. It's when that Novocain is wearing off, you get that tingling feeling. I have that tingling...feeling, all the way up my whole right side from my, split in your lip all the way up to my ear.

Participant 1 noted changes after stroke in his preference to the type of fabric he likes "I like soft things a lot more. Like baby blankets." Whereas Participant 11 noted a change in the foods that he used to like before stroke, due to tactile defensiveness "the texture of the food bothers me now...I used to love pudding and Jell-O. But now...I can't eat it...put it in my mouth and about gag."

Participant 5 shared that due to sensitivity to touch and vibration, she had to change the tools she used to use before stroke "I had the power toothbrush and also the Waterpik" but "because of the sensitivity I switched to manual and floss instead of those two items."

In regards to proprioception, Participant 12 described that he takes additional time to complete activities that involve walking as he keeps looking at his foot to ensure safety "I don't feel it right so I gotta make sure I got it planted."

Altered multisensory processing. Three participants also described unique experiences where they experienced changes in processing multiple sensory stimuli, one of which was 
auditory. Participant 10 described a difficulty in managing multiple sensory stimuli in his environment:

some of my sensory is a delayed reaction almost...it takes longer. Let's say four things happen at the same time, they're going to hit me at four different times...So, the crowd is moving, a lot of conversation, and somebody else will talk to me, my wife will talk to me. And I've got to shut everything out, but it takes time to shut it out.

Those participants still working prior to their stroke noted a difficulty in returning to or maintaining work after due to difficulty processing multiple sensory stimuli. Participant 9 who worked as a karaoke DJ described her attempt at karaoke after her stroke, she admitted that "I love to sing. And I couldn't do that anymore. I couldn't process between what I was hearing and seeing to make the right notes come." This processing change made her work difficult, "I was off time always, slow. And sometimes I would even be off pitch. And as a karaoke DJ, that is not cool." Additionally, Participant 5 shared the difficulty she experienced during work meetings "everybody is talking and trying to pass this or do this, and someone is trying to make a presentation, and this is too much."

Sensitivity to temperature and pressure. Many participants indicated an increase in sensitivity to cold temperatures. Participant 1 described that "I just feel chilly, I don't feel warm and snuggly," and Participant 4 shared "I seem to be a little colder more often than I was before the stroke. Especially my upper body." Yet Participant 2, who is a marathon runner, explained how sensitivity to cold limited his ability to participate in his favorite leisure activity:

I see me very sensitive to the cold... weather like this used to be ideal running weather. Just put gloves and stocking hat on just go out for a run. Used to be something I really 
enjoyed and now just being outside for a short period seems to bother my left side a little more.

Conversely, Participant 11 shared that he sensitive to heat after stroke "I feel it's way hotter outside even in the winter... I've been wearing shorts ever since I had my stroke"

Participant 10 noted an increased sensitivity to pressure on his leg, although this sensation did not carry over to other parts of his body, "I'm very aware of or sensitive to any pressure I put on my right side.... It's real sensitive to that touch.... It's more than just the contact... It's very noticeable."

\section{Experience and Timing of Sensory Changes}

This theme consisted of two categories related to people's personal experience of sensory changes after stroke: temporal nature of sensory changes, and feelings toward sensory changes.

Temporal aspect of sensory changes. The first category in the second theme describes the timing of sensory changes as well as their permanency.

Most participants experienced sensory changes right after their stroke. When referring to his visual changes, Participant 2 indicated that "it was immediately after my stroke." Some participants indicated that their sensory changes didn't occur until well after the stroke. When describing his experience of sensitivity to light and sound, Participant 6 stated, "at least anywhere between one-two years I didn't experience any of these things" Participant 7 indicated a delay in the onset of her sensitivity to sound, "I didn't notice the sensitivity when I was at the hospital, it is definitely happened after I left."

For most of the participants the sensory changes they experienced were ongoing. Participant 1 explicitly stated, "I think after a year or so the temperature one seems to be 
ongoing" when describing his sensitivity to colder temperatures. However, some participants indicated a recovery of some sensory functions. Participant 8 shared "Well I had tingling in my left hand real bad for several years but it finally kinda went away." Participant 11 described the progressive recovery of tactile defensiveness in his mouth as well as taste:

it didn't work at first. After several months it started getting better. It was about three months before I could tell a difference and it was probably nine months before it felt like I could taste something throughout my whole tongue.

Feelings toward sensory changes. In the second category of the second theme, participants shared the personal impact that sensory changes had on them. Some survivors shared the way they handled sensory changes increased their level of fatigue. For example, Participant 12 noted "as the day goes by I get tired" as he kept his eyes on his leg, due to lack of input from the foot, to maintain his safety. Participant 5 shared feeling fatigued when experiencing multiple sensory stimuli at the same time in the church "I got to situations that I feel this is overwhelming, you know, that's...tiring."

Many participants had difficulty understanding the nature of sensory changes and what was happening to them. Participant 11 described his confusion as to why food textures he had enjoyed prior to his stroke now made him gag, “I don't know. Sounds stupid...I don't know, I'm so confused about what is going on." Survivors also described feeling misunderstood by those around them, that people cannot understand what exactly the survivors are going through, Participant 13 noted "one of the hardest things to get my wife to understand, is how tired you are after a stroke." Participant 11 described the difficulty of getting others to understand sensory changes because they aren't easy to see, “people look at me and say, 'You don't look that bad off' but, they don't see in here" as he pointed to his skull. Participant 5 articulated how she has 
difficulty describing sensory changes to other people “It's very different now, I don't know how to describe it, but I cannot get used to it again.”

Finally, participants expressed the fear that they experienced due to sensory changes. Participant 10 described the feeling he gets when he is receiving multiple sensory inputs from his environment, “Anxiety, I almost get anxiety attacks, I gotta get away from it.”

\section{Discussion}

Through this study, researchers aimed to gain a better understanding of the stroke survivors' experience of sensory changes. Participants expressed that they experienced changes in various sensory systems; touch, proprioception, vision, hearing, smell, taste, as well as changes in the tolerance level to the environmental stimuli. Older people experience natural sensory changes (Boyce \& Shone, 2006). However, people in the present study didn't report sensory changes over time prior to stroke. It is possible stroke exaggerates or hastens sensory changes that may occur with aging, however it is also possible stroke causes sensory changes unrelated to age.

A unique finding in this study was the impact of the sensory changes on participants' daily life. Literature has documented the impact on leisure and daily life activities of people with stroke. Most often, the nature of the impact is studied in relation to motor or cognitive changes. Related to sensory impact, previous research studied the impact of changes in touch and proprioception on participation in daily life activities and quality of life among stroke survivors (Doyle et al., 2014; Leopold et al., 2018). This is the first study to explore the sensory nature of the changes other than touch and proprioception in daily life activities. For instance, difficulty in eating could lead to decreased interest in food which in turn may lead to nutritional deficiency and weight loss (Green et al., 2008). Taste and smell changes could also impact the enjoinment 
in dining out with family and friends which may impact social activities or food-related group activities. Due to sensory changes as well, stroke survivors may spend more time completing their daily routines which lead to fatigue and depression (Dutaa et al., 2013; Wallenbert \& Jonsson, 2005).

While participants reported changes in taste and smell immediately after stroke, they noticed sensitivity approximately one-two years after stroke. This finding matches the findings of a case report of two stroke survivors who confirmed that taste and smell changes occurred immediately after stroke and changes were severe in the first three months (Green et al., 2008). However, since the onset of sensory changes post stroke is variable, Heckman et al. (2003) mentioned that stroke survivors rarely reported changes in taste during their hospital stay especially if they experience other changes due to stroke (e.g., motor, cognitive). People tend to report sensory changes later in the recovery process, perhaps because early focus is on survival and it takes time for stroke survivors to reconcile changes affecting daily life. Another possible explanation is that as people return home, sensory changes become more pronounced as people begin to re-engage in daily life situations in its real context after they leave the hospital (Bouffioulx, Arnould, \& Thonnard, 2011). Another explanation could be that people receive more support in the first stage of stroke (Kruithof et al., 2015), and they develop self-reliance later which might change their need to be vigilant of surroundings. Accordingly, it is important to integrate sensory assessments in early stages of rehabilitation and raise the patient's awareness toward sensory changes.

Participants expressed that sensory changes are more subtle than motor changes. Sensory changes were difficult to explain by some of the study participants which might contribute to being hidden for people around them. Additionally, participants demonstrated the lack of 
information regarding sensory changes, which made them skeptical about its nature. This perhaps also contribute to make these changes invisible to other people. These findings expand on previous research where stroke survivors discussed that their somatosensory changes were not addressed in therapy and they were left on their own to accommodate sensory changes after stroke (Doyle et al., 2014). Increasing stroke survivors' awareness of sensory changes during rehabilitation can help addressing these changes earlier in therapy and encourage stroke survivors to develop coping strategies to handle these changes. Moreover, survivors can advocate for their needs regarding sensory changes to improve awareness among people surrounding them.

Consistent with previous research, the sensory system that participants discussed the most was touch (Bolognini et al., 2016; Tyson et al., 2008). It is interesting to note that participants used similar descriptions of what have been reported in the literature. For example, Doyle et al. (2014) stated survivors described their touch changes as "it was asleep" and "Novocain". These words were used by our participants as well. As people were consistent in the description of sensory changes, this may facilitate the development of sensory assessments for stroke population. This research is novel for including sensory changes other than touch. Participants reported sensitivity to sound, light, taste, smell, and pressure. Even though sensitivity to environmental stimuli was a salient topic shared by the current study participants, few researchers have addressed it in the literature.

Recovery of sensory changes was another worth-mentioning finding that emerged from the study data. Most sensory changes reported in the current study were permanent. However, one participant described recovery from tactile sensory changes, and another mentioned improvement in taste sensation over time. Most of the spontaneous recovery in sensory changes 
occurs within the first three months after stroke and could be extend to a year (Julkunen, Tenovuo, Jaaskelainen, \& Hamalainen, 2005). However, previous literature couldn't support the recovery after a year post stroke (Julkunen et al., 2005). It is important to mention that recovery process vary greatly among survivors based on multiple factors (e.g., severity of stroke, age; Connell, 2007), yet we didn't find unique characteristics among the two participants who reported the recovery.

Previous research found that changes in the sensory inputs to the brain can change the somatosensory cortical organization (Connell, 2007). In other words, a possible explanation of the participant's tactile recovery could be linked to brain plasticity. Research regarding brain plasticity in sensory abilities is promising. Ross, Jamali, and Tremblay (2013) suggested that repetitive sound stimulation can improve sound perception. Another research study showed the impact of multisensory stimulation on activating uni-sensory cortical regions (e.g., auditory, visual, somatosensory) after stroke which in turn supports neural plasticity (Polley, Hillock, Spankovich, Popescu, Royal, \& Wallace, 2008). This evidence confirms the importance of rehabilitation in the recovery phase after stroke to support spontaneous recovery and neuroplasticity.

\section{Limitations and Future Directions}

The current study has several strengths and potential future directions for research. This is the first study to investigate stroke survivors' experience of various type of sensory changes. This study recruited stroke survivors who were living in the community for at least a year. Conversely, most previous studies focused on understanding changes stroke survivors experience in the acute stage. It is important to understand how people live their lives after stroke in the 
community and in their natural context. Future research should consider how survivors cope with sensory changes to overcome difficulties that impact their participation in daily life.

Given the complexity of stroke, we acknowledge that sensory changes don't happen separately from other changes such as cognitive and physical changes. In this study we didn't control for other changes which may have impacted on the sensory processing functions and vice versa (Dye, \& Pascalis, 2017). Further research is warranted to account for various changes after stroke.

\section{Conclusion}

In conclusion, the findings of this study confirm the sensory changes stroke survivors experience after stroke and its impact on participation in daily life activities. While we know stroke survivors' experience of somatosensory changes, few studies have sought to understand the lived experience of other sensory changes after stroke and how changes impact their participation in daily life activities. The current study indicated that people experience various sensory changes (i.e., visual, auditory, vestibular, touch, pain, and sensitivity to sensory stimuli) and encounter various difficulties in completing daily life activities due to sensory changes after stroke.

Key messages:

- Health care providers should be aware of stroke survivors' sensory needs and preferences as they support recovery.

- Understanding stroke survivors' sensory changes could help friends, and loved ones modify the home/work environment to support survivors' sensory needs. For instance, if a person experiences sensitivity to light after stroke, dimming lights at home or work could be helpful. 
- Health professionals need to consider sensory changes after stroke and develop measures to capture these changes to improve survivors' satisfaction and quality of life. 


\section{Tables}

\section{Table 1}

Sample interview questions

What changes have you experienced in each sensory system?

Please tell me about unexpected situations that you needed to cope with because of sensory changes.

Please describe your experiences with sound, light, vibration, and touch after stroke?

Explain how sensory changes affect your participation in social activities

How do sensory changes affect the tools that you use on daily

Explain how sensory changes affect your participation in leisure activities 
Table 2

Demographic Information

\begin{tabular}{|c|c|c|c|c|c|c|c|}
\hline Participant & Age & Gender & $\begin{array}{l}\text { Marital } \\
\text { Status }\end{array}$ & Race & $\begin{array}{l}\text { Side of } \\
\text { Stroke }\end{array}$ & $\begin{array}{l}\text { Type of } \\
\text { Stroke }\end{array}$ & $\begin{array}{l}\text { Years since } \\
\text { stroke }\end{array}$ \\
\hline 1 & 65 & Male & Divorced & Caucasian & Left & Ischemic & 4 \\
\hline 2 & 63 & Male & Married & Caucasian & Right & Hemorrhagic & 4 \\
\hline 3 & 64 & Female & Married & Caucasian & Left & Ischemic & 2.5 \\
\hline 4 & 51 & Female & Single & Caucasian & Right & Hemorrhagic & 3 \\
\hline 5 & 74 & Female & Married & Caucasian & Left & Hemorrhagic & 2.7 \\
\hline 6 & 64 & Male & Single & Caucasian & Left & Ischemic & 6 \\
\hline 7 & 65 & Female & Married & Caucasian & Right & Ischemic & 5 \\
\hline 8 & 63 & Male & Single & Caucasian & Right & Ischemic & 7 \\
\hline 9 & 55 & Female & Single & $\begin{array}{l}\text { American } \\
\text { Indian }\end{array}$ & Right & Ischemic & 6 \\
\hline 10 & 69 & Male & Married & Caucasian & Left & Ischemic & 3 \\
\hline 11 & 59 & Male & Married & Caucasian & Left & Ischemic & 1 \\
\hline 12 & 71 & Male & Divorced & $\begin{array}{l}\text { African } \\
\text { American }\end{array}$ & Right & Ischemic & 1.5 \\
\hline 13 & 74 & Male & Married & $\begin{array}{l}\text { African } \\
\text { American }\end{array}$ & Right & Ischemic & 4 \\
\hline
\end{tabular}


Table 3

Example Sensory Changes and Activities impacted

Themes

1. Daily Life Impact of Sensory function changes
Sample of Quotes

"my eyes are sensitive to light and they are watery more than normal before stroke"

"stuff that was bitter...really bothered me. Like vinegary"

"I've dropped more things than I had before because of the numbness in my hand."

"They were sticking pins in me and I couldn't feel it and I was looking at it and thought I should feel it but...I don't feel anything."

"when I am going to lay down, to go to sleep, or if I want to meditate it is still there 'indicating ringing in ear"”

"right after the stroke...the smell of the spices made me nauseous"

"two years after stroke when these sensitivity things came into play."

"This is too much, I don't think I can handle it" 


\section{References}

Alwawi, D. A., Dean, E., Dunn, W. (2018). Exploring Relationships between Fatigue, Motor Changes and Sensory Processing After Stroke. Manuscript Submitted for Publication.

Alwawi, D. A., Dean, E., Dunn, W., Sabata, D. (2018). The Relationship between Sensory Processing and Activity Participation Among Community-Dwelling Stroke Survivors. Unpublished manuscript, Occupational Therapy Education Department, University of Kansas Medical Center, Kansas.

American Occupational Therapy Association (AOTA). Occupational Therapy Practice Framework: Domain and Process (3rd Edition). (2014). American Journal of Occupational Therapy, 68(Supplement_1), S1-S48. doi:10.5014/ajot.2014.682006.

Bailey, J. (2008). First steps in qualitative data analysis: transcribing. Family practice, 25(2), 127-131. doi:10.1093/fampra/cmn003

Benshir, M. (2016). prevalence of vision disorders after stroke: A pilot study to identify the visual needs of stroke patients. Optometry \& Visual Performance, 4 (4), 128-132. Retrieved from http://ovpjournal.org/uploads/2/3/8/9/23898265/ovp44_article_benshir_web.pdf

Bolognini, N., Russo, C., \& Edwards, D. J. (2016). The sensory side of post-stroke motor rehabilitation. Restorative neurology and neuroscience, 34(4), 571-586.

Bouffioulx, É., Arnould, C., \& Thonnard, J. L. (2011). Satisfaction with activity and participation and its relationships with body functions, activities, or environmental factors in stroke patients. Archives of physical medicine and rehabilitation, 92(9), 1404-1410. doi: 10.1016/j.apmr.2011.03.031 
Boyce, J. M., \& Shone, G. R. (2006). Effects of ageing on smell and taste. Postgraduate medical journal, 82(966), 239-241. doi: 10.1136/pgmj.2005.039453

Carlsson, G. E., Möller, A., \& Blomstrand, C. (2009). Managing an everyday life of uncertaintya qualitative study of coping in persons with mild stroke. Disability and rehabilitation, 31(10), 773-782.

Carroll, L. J., Cassidy, J. D., \& Côté, P. (2006). The role of pain coping strategies in prognosis after whiplash injury: passive coping predicts slowed recovery. Pain, 124(1-2), 18-26. doi: 10.1016/j.pain.2006.03.012

Chiti, G., \& Pantoni, L. (2014). Use of Montreal Cognitive Assessment in patients with stroke. Stroke, 45(10), 3135-3140. doi: 10.1161/STROKEAHA.114.004590.

Connell, L. (2008). Somatosensory impairment after stroke: frequency of different deficits and their recovery. Clinical Rehabilitation, 22, 758-767. doi: doi: $10.1177 / 0269215508090674$

Connell, L. A. (2007). Sensory impairment and recovery after stroke (Doctoral dissertation, University of Nottingham).

Connell, L. A., McMahon, N. E., \& Adams, N. (2014). Stroke survivors' experiences of somatosensory impairment after stroke: An Interpretative Phenomenological Analysis. Physiotherapy, 100(2), 150-155. doi:10.5014/ajot.2014.682006

Donnellan, C., Hevey, D., Hickey, A., \& O’Neill, D. (2006). Defining and quantifying coping strategies after stroke: a review. Journal of Neurology, Neurosurgery \& Psychiatry, 77(11), 1208-1218. doi: 10.1136/jnnp.2005.085670. 
Doyle, S. D., Bennett, S., \& Dudgeon, B. (2014). Upper limb post-stroke sensory impairments: the survivor's experience. Disability and rehabilitation, 36(12), 993-1000. doi: $10.3109 / 09638288.2013 .825649$

Doyle, S. D., Bennett, S., \& Dudgeon, B. (2014). Upper limb post-stroke sensory impairments: the survivor's experience. Disability and rehabilitation, 36(12), 993-1000. doi: $10.3109 / 09638288.2013 .825649$

Dunn, W. (1997). The impact of sensory processing abilities on the daily lives of young children and their families: A conceptual model. Infants and Young Children, 9(4), 23-25.

Dunn, W., Little, L., Dean, E., Robertson, S., \& Evans, B. (2016). The state of the science on sensory factors and their impact on daily life for children: A scoping review. OTJR: occupation, participation and health, 36(2_suppl), 3S-26S. doi: $10.1177 / 1539449215617923$.

Dutta, T. M., Josiah, A. F., Cronin, C. A., Wittenberg, G. F., \& Cole, J. W. (2013). Altered taste and stroke: a case report and literature review. Topics in stroke rehabilitation, 20(1), 7886. doi: $10.1310 /$ tsr2001-78

Dye, M. W. G., \& Pascalis, O. (2017). Editorial: The Sensation-Cognition Interface: Impact of Early Sensory Experiences on Cognition. Frontiers in Psychology, 8, 1742. http://doi.org/10.3389/fpsyg.2017.01742

Elo, S. \& Kyngas, H. (2008). The qualitative content analysis process. Journal of Advanced Nursing 62(1), 107-115. doi: 10.1111/j.1365-2648.2007.04569.x

Gentles, S. J., Charles, C., Ploeg, J., \& McKibbon, K. A. (2015). Sampling in qualitative research: Insights from an overview of the methods literature. The Qualitative Report, 20(11), 1772. 
Gijsbers van Wijk, C. M., \& Kolk, A. M. (1997). Sex differences in perceived health. Nederlands tijdschrift voor geneeskunde, 141(6), 283-287.

Goodell, L. S., Stage, V. C., \& Cooke, N. K. (2016). Practical qualitative research strategies: training interviewers and coders. Journal of nutrition education and behavior, 48(8), 578585. doi: 10.1016/j.jneb.2016.06.001

Graneheim, U. H., \& Lundman, B. (2004). Qualitative content analysis in nursing research: concepts, procedures and measures to achieve trustworthiness. Nurse education today, 24(2), 105-112. doi: 10.1016/j.nedt.2003.10.001

Green, T. L., McGregor, L. D., \& King, K. M. (2008). Smell and taste dysfunction following minor stroke: a case report. Can J Neurosci Nurs, 30(2), 10-3.

Grefkes, C., \& Fink, G. R. (2011). Reorganization of cerebral networks after stroke: new insights from neuroimaging with connectivity approaches. Brain, 134(5), 1264-1276. doi: 10.1093/brain/awr033.

Guest, G., Bunce, A., Johnson, L. (2006). How many interviews are enough? An experiment with data saturation and variability. Field Methods, 18, 59-82.

Harrison, R. A., \& Field, T. S. (2015). Post stroke pain: identification, assessment, and therapy. Cerebrovascular Diseases, 39(3-4), 190-201. Doi: 10.1159/000375397

Heckmann, J. G., Heckmann, S. M., Lang, C. J., \& Hummel, T. (2003). Neurological aspects of taste disorders. Archives of neurology, 60(5), 667-671. doi:10.1001/archneur.60.5.667.

Jacobsson, C., Axelsson, K., Wenngren, B. I., \& Norberg, A. (1996). Eating despite severe difficulties: assessment of poststroke eating. Journal of Clinical Nursing, 5(1), 23-31. 
Julkunen, L., Tenovuo, O., Jaaskelainen, S. \& Hamalainen, H. (2005). Recovery of somatosensory deficits in acute stroke. Acta neurologica Scandinavica, 111, 366-72. doi:10.1111/j.1600-0404.2005.00393.x

Kashi, Y., Ratmansky, M., \& Defrin, R. (2017). Deficient Pain Modulation in Patients with Chronic Hemiplegic Shoulder Pain. Pain Practice. doi: 10.1111/papr.12658

Kaye, A. D., Baluch, A., \& Scott, J. T. (2010). Pain management in the elderly population: a review. The Ochsner Journal, 10(3), 179-187.

Kinnealey, M., Oliver, B., \& Wilbarger, P. (1995). A phenomenological study of sensory defensiveness in adults. American Journal of Occupational Therapy, 49(5), 444-451. doi:10.5014/ajot.49.5.444

Koohi, N., Vickers, D. A., Lakshmanan, R., Chandrashekar, H., Werring, D. J., Warren, J. D., \& Bamiou, D. E. (2017). Hearing characteristics of stroke patients: prevalence and characteristics of hearing impairment and auditory processing disorders in stroke patients. Journal of the American Academy of Audiology, 28(6), 491-505.

Kruithof, W. J., Post, M. W., Van Leeuwen, C. M., Schepers, V. P., van den Bos, G. A., \& Visser-Meily, J. (2015). Course of social support and relationships between social support and patients' depressive symptoms in the first 3 years post-stroke. Journal of rehabilitation medicine, 47(7), 599-604. doi:10.2340/16501977-1971

Landi, F., Onder, G., Cesari, M., Zamboni, V., Russo, A., Barillaro, C., ... \& Silvernet-HC study group. (2006). Functional decline in frail community-dwelling stroke patients. European Journal of Neurology, 13(1), 17-23. doi: 10.1111/j.1468-1331.2006.01116.x 
Leopold, D.A., Holbrook, E., Noell, C., \& Mabry, R. (2018). Disorders of taste and smell. Emedicine Medscape [On-line]. Retrieved from https://emedicine.medscape.com/article/861242-overview

Lincoln, Y., \& Guba, E. (1985) Naturalistic inquiry. Beverly Hills, CA: Sage.

MacLean, L. M., Meyer, M., \& Estable, A. (2004). Improving accuracy of transcripts in qualitative research. Qualitative Health Research, 14(1), 113-123. doi: $10.1177 / 1049732303259804$

Paolucci, S., Iosa, M., Toni, D., Barbanti, P., Bovi, P., Cavallini, A., ... \& Pieroni, A. (2015). Prevalence and time course of post-stroke pain: a multicenter prospective hospital-based study. Pain Medicine, 17(5), 924-930. doi:10.1093/pm/pnv019

Patton, M.Q. (2002). Qualitative Research and Evaluation methods, (3rd ed.). Thousand Oaks, CA: Sage Publications.

Pohl, P. S., Dunn, W., \& Brown, C. (2003). The role of sensory processing in the everyday lives of older adults. OTJR: Occupation, Participation and Health, 23(3), 99-106.

Polley, D. B., Hillock, A. R., Spankovich, C., Popescu, M. V., Royal, D. W., \& Wallace, M. T. (2008). Development and plasticity of intra-and intersensory information processing. Journal of the American Academy of Audiology, 19(10), 780-798. Retrieved from: https://doi.org/10.3766/jaaa.19.10.6

Pound, P., Gompertz, P., \& Ebrahim, S. (1999). Social and practical strategies described by people living at home with stroke. Health \& social care in the community, 7(2), 120-128.

Rhoda, A. (2012). Limitations in activity and participation experienced by stroke patients: A qualitative inquiry. South African Journal of Physiotherapy, 68(3), 20-24. doi: 10.4102/sajp.v68i3.20. 
Ross, B., Jamali, S., \& Tremblay, K. L. (2013). Plasticity in neuromagnetic cortical responses suggests enhanced auditory object representation. BMC neuroscience, 14(1), 151. Retrieved from: http:/www.biomedcentral.com/1471-2202/14/151

Sandelowski, M. (2000). Focus on research methods: Whatever happened to qualitative description? Nursing \& Health, 23, 334-340.

Sandelowski, M.: Theoretical saturation. In: Given, L.M. (ed.) The SAGE Encyclopedia of Qualitative Research Methods, vol. 2, pp. 875-876. Sage, Thousand Oaks (2008)

Sandelowski, M. (2010). What's in a name? Qualitative description revisited. Research in Nursing and Health, 33, 77-84. doi: 10.1002/nur.20362.

Schimmel, M., Voegeli, G., Duvernay, E., Leemann, B., \& Müller, F. (2017). Oral tactile sensitivity and masticatory performance are impaired in stroke patients. Journal of oral rehabilitation, 44(3), 163-171. doi: 10.1111/joor.12482

Sullivan-Bolyai, S., Bova, C., \& Harper, D. (2005). Developing and refining interventions in persons with health disparities: The use of qualitative description. Nursing outlook, 53(3), 127-133. doi: 10.1016/j.outlook.2005.03.005

Tong, A., Sainsbury, P., \& Craig, J. (2007). Consolidated criteria for reporting qualitative research (COREQ): a 32-item checklist for interviews and focus groups. International journal for quality in health care, 19(6), 349-357. doi: 10.1093/intqhc/mzm042

Tyson, S. F., Hanley, M., Chillala, J., Selley, A. B., \& Tallis, R. C. (2008). Sensory loss in hospital-admitted people with stroke: characteristics, associated factors, and relationship with function. Neurorehabilitation and Neural Repair, 22(2), 166-172. doi: $10.1177 / 1545968307305523$ 
U.S. Census Bureau (2017a). U.S. Census Bureau Quick Facts. Retrieved from https://www.census.gov/quickfacts/fact/table/wyandottecountykansas/BPS030216.

Wallenbert, I., \& Jonsson, H. (2005). Waiting to get better: A dilemma regarding habits in daily occupations after stroke. American Journal of Occupational Therapy, 59(2), 218-224. doi:10.5014/ajot.59.2.218

Widar, M., Ek, A. C., \& Ahlström, G. (2004). Coping with long-term pain after a stroke. Journal of pain and symptom management, 27(3), 215-225. doi:

0.1016/j.jpainsymman.2003.07.006 


\section{Appendix A: Student Training}

For interviewer training we followed the following steps:

1. For phase one, all students completed the human subject research training offered by the university. By completing the training, the students became familiar with the ethical standards to conduct research and learned the rules and policies to maintain participant's confidentiality.

2. For phase two, the lead researcher reviewed with the students the qualitative research fundamentals and data collection procedures.

3. For phase three, the student interviewer was trained by first listening to recorded interviews and reading the transcripts that the lead researcher had conducted when pilot testing procedures. The lead researcher provided feedback on opportunities and techniques for probing and also discussed the rationale for the interview questions when needed.

4. For phase four, the student interviewer observed the lead researcher during an interview and the student was allowed to ask questions and ask for clarifications after the interview.

5. Lastly, the lead researcher observed the interviewer conducting an interview and provided feedback and reflected on what the interviewer did well and any areas of improvement.

We followed the 5-phase Training for the coders as follows:

1. Coders followed the same two phases interviewer student followed.

2. The third phase start with the lead researcher reviewing the coding process adapted from Graneheim and Lundman (2004). Then, coders were given examples of text 
segments and how to develop a coding dictionary for that text. During research group meetings, the lead researcher demonstrated how to apply the coding dictionary on a selected segment of a transcript; then coders jointly practiced the process on selected transcripts.

3. When the coders became familiar with the coding process, the lead researcher provided the same transcript for all coders to code independently before the next meeting. At the meeting, the lead researcher went through the transcript line by line and asked the coders how they coded each part. If there were any discrepancies between coders on coding text segments, the group discussed these areas to reach consensus on how the text segments should be coded.

4. Then, each coder individually coded different transcripts and discussed the process in a team meeting. 


\section{Appendix B: Comprehensive Examination One}

Stroke and Oral Hygiene: Factors Influencing Effectiveness of Toothbrushing 


\begin{abstract}
This study examined toothbrushing ability after stroke when using the non-dominant hand to manipulate a manual tooth brush. Ten right-handed participants who had had left stroke were recruited. The Oral Hygiene Index Score evaluated plaque levels before and after brushing. Three tests of sensorimotor skills (Finger Tapping, Nine-hole peg and Jebsen Hand Function) estimated functional use of each subject's ipsilesional, left hand; the FuglMeyer test of motor recovery estimated residual functional use of the contralesional, dominant (right) arm.

Despite this finding, plaque scores in people with stroke after brushing $($ Median $=1.68)$ differed from the plaque score before brushing (Median $=2.53), Z=-2.67, \mathrm{p}=.008$, indicating stroke participants were able to remove plaque using manual toothbrush with their left, non-dominant hand. This study opens a new door for collaboration between dental hygienists and occupational therapists in improving the oral hygiene for people after stroke.
\end{abstract}




\section{Introduction}

Each year, approximately 15 million people worldwide are affected by stroke (Kwok, Mcintyre, Janzen, Mays, \& Teasel, 2015). Stroke is defined as a cerebral focal injury leads to neurological deficits, and is a major cause of disability and death globally (Sacco et al., 2013). Stroke may affect multiple areas of the brain including the body's ability to perform motor, cognitive, and sensory functions (Duncan et al., 2005). Changes in functional abilities impact an individual's performance in completing activities of daily living (ADLs), such as eating, dressing, and personal grooming. Occupational therapy is a profession that helps people to do what they want to do in different areas of their lives such as ADLs, work, leisure activities, and education (American Occupational Therapy Association, 2016). According to Occupational Therapy Practice Framework: Domain and Process (American Occupational Therapy Association, 2014) oral hygiene is an ADL.

Oral hygiene is critical to maintain oral health and the health of other body systems (Stein and Henry, 2009). Plaque on tooth surfaces allows bacteria to breed and can cause dental caries and periodontal disease, potentially leading to more serious consequences such as tooth and gum loss (Petersen, 2003). The primary method for daily oral hygiene is to remove plaque by toothbrushing (Hansen \& Gjermo, 1971). Efficient plaque removal depends on brush design, frequency and duration of brushing, and the skill of the user. The last variable is most pertinent to the present study; Zhu, McGrath, McMillan, \& Li (2008) found that nearly $84 \%$ of study participants who had a stroke also had difficulty brushing their teeth during the first month of hospital stay after stroke, and about 50\% still had problems six months post-stroke. A possible contributing factor was difficulty using a single hand appropriately to brush their teeth (Hunter, 
Clarkson, Fraser, \& MacWalter, 2006). Individuals reported concern for poor grip, inability to use the affected hand, and ineffective use of the "unaffected" hand to brush efficiently. Yet a more recent report on stroke and oral health fails to even mention dexterity impairments as a significant barrier to maintaining oral health (Dickinson, 2012).

Stroke can result in weakness and/or paralysis of the arm/hand opposite to the brain injury (i.e. left hemisphere stroke produces right arm/hand paralysis), which is a well-recognized source of disability (Nakayama, Jorgensen, Raaschou, \& Olsen, 1994). In right-handed people, a left hemisphere stroke impairs their dominant (right) hand; clinicians apply a variety of therapeutic interventions aimed at restoring function in the dominant hand, but restoration is hard to achieve (Barreca, Wolf, Fasoli, \& Bohannon, 2003). While researchers and clinicians have believed that one hand remains "unaffected"(Sunderland, Bowers, Sluman, Wilcock, \& Ardron, 1999), emerging evidence indicates the contrary; both the "affected" and the "unaffected" hands exhibit movement and strength differences after stroke (Kitsos, Hubbard, Kitsos, \& Parsons, 2013). Therefore, in this paper, we will use "less affected" hand to refer to the "non-affected" hand. Parsaee, Dehkordi, Dadgoo, \& Akbarfahimi (2014) reported reduced speed of movement, reduced range of motion, lack of dexterity, difficulties in reaching and manipulative tasks, poor coordination, and abnormal timing of muscle action of the "unaffected hand" after stroke. These skills are necessary for many ADLs, including toothbrushing.

Literature suggests different hypotheses regarding the function of less affected hand after stroke (Zhang et al., 2015). The first hypothesis is that the function of less affected hand decreases to varying degree after stroke; the larger the impairment exhibited by the affected hand, the larger the impairment exhibited by the less affected hand (Zhang et al., 2015). The second hypothesis suggested that people after stroke exhibit more flexible use of the less affected 
hand compared with people without stroke (Wetter, Poole, \& Haaland, 2005). People after stroke use less affected hand in daily activities more frequently to replace the role of affected hand. Left hemisphere stroke in right-handed people often results in profound motor impairment of the dominant (right) hand. In this case, there also often is an increased reliance on the non-dominant (left) hand to maintain independence in daily tasks (Wetter, Poole, \& Haaland, 2005).

Occupational therapists (OTs) collaborate with the clients they serve, health care professionals, and caregivers to improve the client's participation in daily occupations. Previous research suggested the importance of the OT's role on the oral care team as educator, evaluator, and oral care consultant (Banovitz, Bellah, and Lion, 2015). Although OTs are equipped with the knowledge and skills to collaborate with dental professionals, OTs are not widely integrated in oral care teams. Bellomo, et al. (2005) found significant improvement in oral hygiene measures for older people in long term care facilities, when OTs became part of oral care team. In that study, OTs helped people who had hemiplegia to position themselves at a sink to brush their teeth, and taught them a one-handed technique to squeeze toothbrush. OTs can modify the oral hygiene tools or environment to improve a client's oral hygiene (Bellomo, et al., 2005). Additionally, there is a critical need to identify potential rehabilitation approaches directed toward the non-dominant hand in order for OTs to better facilitate increased performance in toothbrushing after stroke, which is important to future patient care.

The purpose of this study was to examine toothbrushing ability using the non-dominant hand after left stroke.

\section{Research questions}

1. Characterize differences in non-dominant hand function between our group of adults who have had a stroke as compared to age-matched peers. We hypothesize participants will 
demonstrate greater impairment in hand function when using their non-dominant left hand compared with age-matched controls who have not had a stroke.

2. To what extent is non-dominant hand function related to efficiency using a manual toothbrush after left hemisphere stroke? We hypothesize participants with greater function of the less affected non-dominant hand will demonstrate a greater reduction in plaque levels after brushing.

3. Does a functional motor assessment of the contralateral dominant hand after left hemisphere stroke relate to toothbrushing efficiency using the ispilesional non-dominant hand? We hypothesize participants with greater function of the affected hand also will demonstrate a greater reduction in plaque levels after brushing with the less affected hand.

\section{Methods}

\section{Study Design and Participants}

This is a cross sectional study design approved by the University IRB. Following informed consent, ten participants were recruited from a University Hospital. Participants were included in the study if they were 18 years of age or older, right-handed, had had a single unilateral left hemisphere stroke, were able to grasp objects using left (non-dominant) hand, had at least $50 \%$ of their natural teeth (10-12 teeth on top and 10-12 teeth on bottom), and a Montreal Cognitive Assessment (MoCA; (Nasreddine et al., 2005) score of 26 or greater. Exclusion criteria included history of central nervous disease other than stroke, history of bilateral stroke, presence of non-neurological disease/injury (e.g., arthritis or fractures) causing motor disability in arms/hands, severe aphasia, absence of at least $50 \%$ of teeth (less than 10 teeth on top and less than 10 teeth on bottom), and a MoCA score less than 26. 


\section{Instruments/materials}

- The Montreal Cognitive Assessment (MoCA) ((Nasreddine et al., 2005) is a screening tool used to detect mild cognitive dysfunction in adults. The MoCA is a 30-point scale divided into 7 cognitive subtests: visuo-executive, naming, attention, language, abstraction, delayed recall, and orientation. The MoCA is valid and has excellent testretest and interrater reliability (Toglia, Fitzgerald, O'Dell, Mastrogiovanni, \& Lin, 2011).

- The Edinburgh Handedness Inventory (Oldfield, 1971) is a questionnaire assessing hand dominance for everyday activities. The Edinburgh Handedness Inventory is valid and has good test-retest reliability (Ransil \& Schachter, 1994). Participants were asked to report which hand they prefer to use in common everyday activities such as writing, drawing, throwing, using a spoon, etc.

- Jamar ${ }^{\circledR}$ Hydraulic Hand Dynamometer (Bertrand, et al., 2007): Used to assess grip strength of a participant's left hand. This Hand Dynamometer is valid for use with stroke patients and has excellent test-retest reliability (Hamilton, McDonald, \& Chenier, 1992). The reported score was the mean of three successive grip strength trials.

- A Finger Tapping Test (Heller, Wade, Wood, Sunderland, Hewer, \& Ward, 1987) assessed basic motor control and integrity of the central nervous system. It is valid for use with people who have had a stroke, and the test has a high degree of test-retest reliability. Participants were instructed to use their non-dominant hand index finger to "tap as fast as you can" for 10 seconds. During administration, participant's palm rest flat on the board, with fingers extended, and the index finger rests on a lever attached to a mechanical counting device to record the number of finger taps. Participants completed $5 \times 10$ second trials, and were allowed a 30 -second rest period in between trials. 
- The Jebsen Hand Function Test (JHFT) (Jebsen, Taylor, Trieschmann, Trotter, \& Howard, 1969) was used to assess common daily tasks done with only one hand.. The JHFT is a reliable measure that demonstrates sensitivity to detecting weakness in the "unaffected" arm (Spaulding, 1988). The JHFT is comprised of 7 subtests, including writing, card turning, picking up small objects, stacking checkers, simulated feeding, moving light objects, and moving heavy objects. The writing task was omitted for all participants due to dependence on hand dominance and level of education (Beebe \& Lang, 2009). Participants completed the JHFT using only their non-dominant (left) hand. The reported score for each subtest was time in seconds to complete the task. Less time to compete the tasks indicates greater hand function.

- Nine-Hole Peg Test (NHPT) (Felder eta al., 1994) is used to measure hand dexterity. Participants pick 9 ((0.25 inches) in diameter and (1.25 inches) long) wooden pegs up one at a time and place each into one of 9 holes ( 0.5 inches deep) as quickly as possible. They then remove the pegs from the holes one at a time. Participants completed each trial using their non-dominant (left) hand. Scores are based on the time taken to complete the activity recorded in seconds. More rapid task completion indicates better hand dexterity. NHPT demonstrates excellent test retest and interrater reliability (Chen, Chen, Hsueh, Huang, \& Hsieh, 2009).

- Fugl-Meyer Motor Assessment (FMA) (Fugl-Meyer et al., 1975) is a widely-used assessment measure to evaluate motor impairment after stroke (Gladstone et al, 2002). Here, the FMA was used to evaluate post-stroke function of the affected (right) arm. FMA sections include measures of the hemiplegic arm function, leg function, balance, light touch sensation, proprioception, range of motion, and joint pain. Each section was 
scored separately. Since our focus is on arm function, we only assessed and scored the arm function section. The maximum score for arm function is 66 points, with higher scores indicating greater function. Evidence supports the FMA is valid and sensitive for detecting arm function after stroke, and that it shows an excellent test-retest reliability (Sullivan et al., 2011).

- Oral Hygiene Index (OHI) (Green \& Vermillion, 1960) is comprised by a combined score of debris index and calculus index, by evaluating each tooth within the oral cavity. Debris (plaque) is defined as "the soft foreign material consisting of mucin, bacteria, and food that is loosely attached to the tooth surface" (Podshadley \& Haley, 1968, p. 259). If plaque is not removed regularly, it hardens to form calculus (Green \& Vermillion, 1960). We evaluated each tooth for debris and calculus on the buccal and lingual surfaces using ordinal scales (Table 1). An oral hygienist scored each tooth, then calculated a mean plaque index by adding the score of plaque on the facial, buccal, and lingual surfaces of all teeth, and dividing by the number of teeth examined (Figure 1). All teeth on upper (maxillary) and lower (mandibular) arches were evaluated (Figure 2). The surfaces of crowns and bridges were excluded from the analysis. The difference in pre-bushing and post-brushing scores was calculated for each participant to determine efficiency of toothbrushing.

<insert Table 1 here $>$

$<$ insert Figure 1 here $>$

$<$ insert Figure 2 here $>$ 


\section{Procedure}

Participants were instructed not to brush teeth 12 hours prior to the visit to ensure time for plaque to build up on the teeth. Participants completed screening and testing procedures in a quiet, distraction-free university laboratory.

A researcher evaluated the participant for eligibility to participate in the study upon arrival. A registered dental hygienist conducted oral screening. Participants were seated comfortably and asked to remove any dental appliances. The oral screening determined participant eligibility and confirmed the participant was not allergic to dental disclosing agent used in this study.

Eligible participants engaged in sensorimotor tests and were asked about oral hygiene routines, frequency of toothbrushing, and type of toothbrush. The dental hygienist used a cotton swab to apply disclosing agent to all tooth surfaces, and then recorded a plaque index score for each tooth using the Oral Hygiene Index.

Participants were instructed to stand in front of a mirror and brush their teeth using a manual toothbrush using only their non-dominant (left) hand continuously for a timed two-minute period. Toothpaste and water were not used, in order to assure plaque removal occurred exclusively from brushing. The participants were instructed to brush each quadrant of their mouth for thirty seconds, with the researcher using a stop watch to announce 30 -second intervals. No other instructions were given. After brushing, the oral hygienist used a disclosing agent again to obtain the post-brushing OHI score.

\section{Data Analysis}

We used IBM: SPSS (v. 23) to perform statistical analysis. All statistical tests of hypotheses employed a level of significance of alpha $=0.05$. A one sample t-test examined 
whether a significant difference between our sample and the population norms was present in performance of sensorimotor tests. Wilcoxon Signed rank test for two related samples determined the effectiveness of toothbrushing while using the non-dominant hand. Spearman's rank correlation examined the relation of $\mathrm{OHI}$ score and the results of sensorimotor testing. We also conducted the non-parametric Friedman test to examine statistically differences among plaque scores for different tooth surfaces and arches (maxillary lingual, maxillary facial, maxillary buccal, mandibular lingual, mandibular facial, mandibular buccal). Unless otherwise noted, data were expressed as means \pm 1 standard deviation (SD).

\section{Results}

Ten participants ( $56 \pm 11$ years), 5 males and 5 females, who all had a left hemisphere stroke (11 \pm 9 years earlier) participated in the study. Of the 10 participants, there were 9 ischemic and 1 hemorrhagic strokes. Most participants (60\%) reported using a manual toothbrush, while $40 \%$ reported using a powered toothbrush.

Results showed OHI score after brushing $(\mathrm{Mdn}=1.68)$ significantly differed from the OHI score before brushing $(\mathrm{Mdn}=2.53), \mathrm{Z}=-2.67, p=.008$. There were no statistically significant differences between the plaque scores of different tooth surfaces (buccal and lingual), $\chi^{2}(3)=4.99, p=0.18$. Additionally, there were no statistically significant differences between the plaque scores of different mouth arches (upper $\operatorname{arch}=$ maxillary, lower $\operatorname{arch}=$ mandibular $)(\mathrm{Z}=$ $-1.34, p=0.18)$.

Scores of dexterity tests from our sample and those of age-matched individuals without stroke who also using their non-dominant left hand appear in Table 2. Results showed significant differences between participants' scores from card turning $(\mathrm{M}=18.73, \mathrm{SD}=12.14)$, simulated feeding $(\mathrm{M}=18.73, \mathrm{SD}=12.140)$, and moving heavy objects $(\mathrm{M}=18.73, \mathrm{SD}=12.14)$ compared 
with the general population $[\mathrm{t}(9)=3.42, p=.008 ; \mathrm{t}(9)=2.23, p=.05 ; \mathrm{t}(9)=2.25, p=.05]$. Participants who had a stroke needed more time to complete NHPT $(\mathrm{M}=26.6, \mathrm{SD}=2.76 ; \mathrm{t}$ (9) $=8.73, p<0.001)$ when compared with people who have not had a stroke using their nondominant, left hand.

$<$ insert Table 2 here $>$

Spearman Rank correlation between change in OHI and the sensorimotor tests showed that there is no correlation with OHI change score (Table 3). Additionally, the correlation between plaque score and FMA score was also non-significant. There was a significant negative correlation between JHFT score and FMA score, that is persons having a lower score in JHFT (better function), showed a higher score in FMA (better function) $\mathrm{r}_{\mathrm{s}}=-0.652, p=0.04$. Plaque score demonstrated a significant correlation with years since stroke $\left(\mathrm{r}_{\mathrm{s}}=.571, p=0.04\right)$, that is the longer since the person had the stroke, the more plaque he/she removed through brushing.

We also ran correlations between each subtest of JHFT and the OHI score. "Simulated feeding" exhibited a statistically significant negative correlation with change in $\mathrm{OHI}\left(\mathrm{r}_{\mathrm{s}}=-0.68\right.$, $p=0.04$ ), that is participants with higher scores on this subtest tended to have less change in OHI. $<$ insert Table 3 here $>$

\section{Discussion}

To our knowledge, this is the first study to examine toothbrushing ability using nondominant hand among the post-stroke population. This study found individuals who sustained a left hemisphere stroke and are right hand dominant can remove plaque effectively using their non-dominant, less affected left hand. Our results also showed that participants with better function in their affected hand (measured by FMA) also demonstrated better function in the less affected hand (measured by JHFT). Kenney et al. (1975) suggests manual dexterity is very 
important in demonstrating good oral hygiene. Our findings didn't support the correlation between the changes in OHI score and dexterity skills.

It is not uncommon for people after stroke to resort to using the less-affected upper extremity for daily activities, particularly when the affected extremity is more severely impaired. Prior research suggests a positive correlation between affected hand impairment and lessaffected hand function in the execution of skilled task (Zhang et al., 2015), meaning greater impairment of the affected hand is associated with reduced dexterity of the less-affected hand. Our results are consistent with previous work, but we did not find that decreased function in the less-affected hand translated to poorer toothbrushing ability, as suggested by previous literature (Kenney et al., 1975). We believe perhaps that the sensorimotor tests used (i.e., JHFT and NHPT) do not accurately represent the skill of toothbrushing. Toothbrushing involves more than fingers dexterity skills. Consideration must also be given to the individual's need to grasp toothbrush and move it back and forth, up and down to brush all teeth surfaces which mainly comprises wrist and shoulder range of motion (Schaefer and Wex, 2015). This could perhaps explain the absence of correlation between toothbrushing and dexterity tests, and support the correlation between $\mathrm{OHI}$ and "simulated feeding" as both tasks are predicated on use of shoulder and wrist movements.

The literature also suggests handedness plays an important role in the outcome of oral hygiene (Kenney et al., 1975; Padilha et al., 2007). Our study showed no-correlation between dexterity tests and plaque scores using the left, non-dominant hand. Our results are consistent with another study that reported older individuals demonstrated a highly correlation between dexterity of the right, dominant hand and plaque score and no correlation between left, nondominant hand dexterity and plaque scores (Padilha et al., 2007). 
Toothbrushing is a learned skill that individual learn over time through repetition and practice (Aunger,2007). Therefore, toothbrushing creates its own internal schema in the brain as a habit or routine behavior (Aunger,2007). A Schema is created for familiar activities to make it easier for the individual to retrieve information automatically related to motor sequence and action organization. Individual after stroke may have trouble complete toothbrushing using the dominant hand they used to use before the stroke as a result of the motor and sensory changes. However, the person may still have a deeply ingrained neuronal model for toothbrushing scaffold the development of the other hand's performance. This could perhaps explain the correlation we found between longer post-stroke experience and greater plaque removal after brushing. The availability of toothbrushing schema and practice using the less affected hand may have enabled our longer post-stroke subjects to improve effectiveness of using their less affected hand over time, as has been suggested in the literature for other tasks (Duque, Mazzocchio, Stefan, Hummel, Olivier, \& Cohen, 2008; Serrien \& Strens, 2004).Brushing using the non-dominant hand after stroke may feel awkward first, but using the available toothbrushing schema over time support using the non-dominant hand in toothbrushing.

A previous study by Carery et al., (2002) suggested practice does play an important role in improving the function of the less affected hand after stroke. Takeuchi and Izumi (2012) demonstrated that the activity of the contralesional side of the brain is increased during functional activities compared with its role in people without stroke. The longer the post-stroke interval, the greater the opportunity the individual has to practice using the less affected hand in daily activities. However, increased maladaptive use of the less affected hand could lead to a poor motor function of the affected and the less affected, in addition to postural complications (Takeuchi and Izumi, 2012). In order to avoid these complications and facilitate skill acquisition 
in toothbrushing using the less affected hand, OTs need to be integrated into the oral health care team to facilitate proper practice of the skill.

The literature supports powered toothbrushes as being able to remove more plaque than manual toothbrushing in healthy individuals using their dominant hand; however, it is uncertain whether the same would hold true with the stroke population. While dental professionals recommend some form of a powered toothbrush for patients who have physical disabilities (Bodnar et al., 2008 ), post stroke hemiparesis presents a unique challenge particularly when it affects the dominant hand, as there exists an aspect of relearning and practicing using the non-dominant hand. In the present study, our subjects demonstrated the ability to reduce plaque by manual toothbrushing using their left-non dominant hand. Utilizing intact schemas with guided practice may be helpful in facilitating more effective manual toothbrushing. Giving patients with stroke opportunities to use the less affected hand in many daily activities may directly enhance rehabilitation of the affected hand (Zhang et al., 2015), increase motivation, enhance self-esteem, and speed functional recovery.

\section{Conclusion}

Participants in our study were able to remove plaque efficiently using their non-dominant hand holding a manual toothbrush. Our study supports that people were able to remove plaque efficiently using the non-dominant, less affected. While there was a correlation between the functional capacity of the affected hand and the manual dexterity of the less-affected hand, this relationship was not reflected on participant's ability to remove plaque using the less-affected hand. If a client chooses to use a manual toothbrush, therapists should examine functional capacity of both the affected and less-affected hands to determine which to use for brushing 
Our finding suggest greater length from initial stroke onset provides more opportunity to practice using the less affected hand in toothbrushing. In this regard, OTs role is essential in oral health care team and this study opens a new door for interprofessional collaboration between dental hygienists and OTs, focused on improving oral hygiene of people after stroke. Rehabilitation of the less affected hand warrants additional consideration, particularly for specific tasks requiring skilled use of the hands. 


\section{References}

American Occupational Therapy Association. (2014). Occupational therapy practice framework: Domain and process. American Journal of Occupational Therapy, 68, S1-S48. doi:10.5014/ajot.2014.682006

Aunger, R. (2007), Tooth brushing as routine behaviour. International Dental Journal, 57, 364376. doi:10.1111/j.1875-595X.2007.tb00163.X

Banovitz, Lauryn J.; Bellah, Liberty; and Lion, Rosemarie, "Oral Wellness: Using Occupational Therapy to Enhance Oral Hygiene Delivery in Long-Term Care" (2015). Master's Theses and Capstone Projects. Paper 142.

Barreca, S., Wolf, S. L., Fasoli, S., \& Bohannon, R. (2003). Treatment interventions for the paretic upper limb of stroke survivors: a critical review. Neurorehabilitation and neural repair, 17(4), 220-226.doi: 10.1177/0888439003259415

Beebe, J. A., \& Lang, C. E. (2009). Relationships and responsiveness of six upper extremity function tests during the first six months of recovery after stroke. J Neurol Phys Ther, 33(2), 96-103. doi: 10.1097/NPT.0b013e3181a33638

Bellomo, F., Preux, F. D., Chung, J. P., Julien, N., Budtz-Jørgensen, E., \& Müller, F. (2005). The advantages of occupational therapy in oral hygiene measures for institutionalised elderly adults. Gerodontology, 22(1), 24-31.

Bertrand, A. M., Mercier, C., et al. (2007). Reliability of maximal static strength measurements of the arms in subjects with hemiparesis. Clin Rehabil 21(3): 248-257.doi:

\section{$10.1177 / 0269215506070792$}

Chen, H. M., Chen, C. C., Hsueh, I. P., Huang, S. L., \& Hsieh, C. L. (2009). Test-retest reproducibility and smallest real difference of 5 hand function tests in patients with 
stroke. Neurorehabilitation and neural repair, 23(5), 435-440.

doi:10.1177/1545968308331146

Dickinson, H. (2012). Maintaining oral health after stroke. Nurs Stand, 26(49), 35-39. doi: 10.7748/ns2012.08.26.49.35.c9233

Duque, J., Mazzocchio, R., Stefan, K., Hummel, F., Olivier, E., \& Cohen, L. G. (2008). Memory formation in the motor cortex ipsilateral to a training hand. Cerebral Cortex, 18(6), 13951406.doi: https://doi.org/10.1093/cercor/bhm173

Felder, R., James, K., Brown, C., Lemon, S., \& Reveal, M. (1994). Dexterity testing as a predictor of oral care ability. Journal of the American Geriatrics Society, 42(10), 10811086.

Fugl-Meyer, A. R., Jaaskc, L., Layman, I., Olsson, S., \& Stcglind, S. (1975). The post-stroke hemiplegic patient. 1. a method for evaluation of physical performance. Scand J Rehab Med, $7(13), 31$.

Gladstone, D. J., Danells, C. J., \& Black, S. E. (2002). The Fugl-Meyer assessment of motor recovery after stroke: a critical review of its measurement properties. Neurorehabilitation and neural repair, 16(3), 232-240.doi: 10.1177/154596802401105171

Green, J., \& Vermillion, J. (1960). The oral hygiene index: a method for classifying oral hygiene status. J Am Dent Assoc, 61(172), 10.

Hamilton, G. F., McDonald, C., \& Chenier, T. C. (1992). Measurement of grip strength: validity and reliability of the sphygmomanometer and jamar grip dynamometer. $J$ Orthop Sports Phys Ther, 16(5), 215-219. doi:10.2519/jospt.1992.16.5.215 
Hansen, F., \& Gjermo, P. E. R. (1971). The plaque-removing effect of four toothbrushing methods. European Journal of Oral Sciences, 79(4), 502-506. doi: 10.1111/j.16000722.1971.tb02044.x

Heller, A. N. D. R. E. W., Wade, D. T., Wood, V. A., Sunderland, A., Hewer, R. L., \& Ward, E. (1987). Arm function after stroke: measurement and recovery over the first three months. Journal of Neurology, Neurosurgery \& Psychiatry, 50(6), 714-719.

Hunter, R. V., Clarkson, J. E., Fraser, H. W., \& MacWalter, R. S. (2006). A preliminary investigation into tooth care, dental attendance and oral health related quality of life in adult stroke survivors in Tayside, Scotland. Gerodontology, 23(3), 140-148. doi: 10.1111/j.1741-2358.2006.00125.x

Jebsen, R. H., Taylor, N., Trieschmann, R., Trotter, M., \& Howard, L. (1969). An objective and standardized test of hand function. Archives of Physical Medicine and Rehabilitation, $50(6), 311$.

Kenney, E. B., Saxe, S. R., Lenox, J. A., Cooper, T. M., Caudill, J. S., Collins, A. R., \& Kaplan, A. (1976). The relationship of manual dexterity and knowledge to performance of oral hygiene. Journal of periodontal research,11(2), 67-73.doi: 10.1111/j.16000765.1976.tb00053.x

Kitsos, G. H., Hubbard, I. J., Kitsos, A. R., \& Parsons, M. W. (2013). The Ipsilesional Upper Limb Can Be Affected following Stroke. The Scientific World Journal, 2013.

Kwok, C., McIntyre, A., Janzen, S., Mays, R., \& Teasell, R. (2015). Oral care post stroke: a scoping review. Journal of oral rehabilitation, 42(1), 65-74.doi: 10.1111/joor.12229 
Nakayama, H., Jorgensen, H. S., Raaschou, H. O., \& Olsen, T. S. (1994). Recovery of upper extremity function in stroke patients: The Copenhagen Stroke Study. Arch Phys Med Rehabil, 75(4), 394-398.

Nasreddine, Z. S., Phillips, N. A., Bedirian, V., Charbonneau, S., Whitehead, V., Collin, I., .. . Chertkow, H. (2005). The Montreal Cognitive Assessment, MoCA: a brief screening tool for mild cognitive impairment. J Am Geriatr Soc, 53(4), 695-699. doi: 10.1111/j.15325415.2005.53221.x

Noskin, O., Krakauer, J. W., Lazar, R. M., Festa, J. R., Handy, C., O’Brien, K. A., \& Marshall, R. S. (2008). Ipsilateral motor dysfunction from unilateral stroke: implications for the functional neuroanatomy of hemiparesis. Journal of Neurology, Neurosurgery \& Psychiatry, 79(4), 401-406.doi: 10.1136/jnnp.2007.118463

Parsaee, M., Dehkordi, S. N., Dadgoo, M., \& Akbarfahimi, M. (2014). Impaired Ipsilateral Upper Extremity Dexterity and Its Relationship with Disability in Post-Stroke Right Hemiparesis. Journal of Rehabilitation Sciences and Research, 1(3), 47-51.

Petersen, P. E. (2003). The World Oral Health Report 2003: continuous improvement of oral health in the 21 st century--the approach of the WHO Global Oral Health Programme. Community Dent Oral Epidemiol, 31 Suppl 1, 3-23.

Podshadley, A. G., \& Haley, J. V. (1968). A method for evaluating oral hygiene performance. Public Health Rep, 83(3), 259-264.

Ransil, B. J., \& Schachter, S. C. (1994). Test-retest reliability of the Edinburgh Handedness Inventory and Global Handedness preference measurements, and their correlation. Percept Mot Skills, 79(3 Pt 1), 1355-1372. doi:10.2466/pms.1994.79.3.1355 
Sacco, R. L., Kasner, S. E., Broderick, J. P., Caplan, L. R., Connors, J. J., Culebras, A., . . . Metabolism. (2013). An updated definition of stroke for the 21 st century: a statement for healthcare professionals from the American Heart Association/American Stroke Association. Stroke, 44(7), 2064-2089. doi:10.1161/STR.0b013e318296aeca

Schaefer, M., Wex, S. (2015). Activity Analysis - Brushing Teeth. Retrieved from http://motbrushingteeth.tumblr.com/

Serrien, D. J., Strens, L. H., Cassidy, M. J., Thompson, A. J., \& Brown, P. (2004). Functional significance of the ipsilateral hemisphere during movement of the affected hand after stroke. Experimental neurology, 190(2), 425-432.doi: 10.1016/j.expneurol.2004.08.004

Shadmehr, R., \& Mussa-Ivaldi, F. A. (1994). Adaptive representation of dynamics during learning of a motor task. The Journal of Neuroscience, 14(5), 3208-3224.

Spaulding, S. J. (1988). Jebsen Hand Function Test: performance of the uninvolved hand in hemiplegia and of right-handed, right and left hemiplegic persons. Archives of Physical Medicine and Rehabilitation, 69(6), 419-422.

Stein, P., \& Henry, R. (2009) Poor oral hygiene in long-term care. American Journal of Nursing, $109(6), 44-50$

Sullivan, K. J., Tilson, J. K., Cen, S. Y., Rose, D. K., Hershberg, J., Correa, A., . . Duncan, P. W. (2011). Fugl-Meyer assessment of sensorimotor function after stroke: standardized training procedure for clinical practice and clinical trials. Stroke, 42(2), 427-432. doi:10.1161/STROKEAHA.110.592766

Sunderland, A., Bowers, M. P., Sluman, S. M., Wilcock, D. J., \& Ardron, M. E. (1999). Impaired dexterity of the ipsilateral hand after stroke and the relationship to cognitive deficit. Stroke, 30(5), 949-955. 
Takeuchi, N., \& Izumi, S. I. (2012). Maladaptive plasticity for motor recovery after stroke: mechanisms and approaches. Neural plasticity, 2012.

Toglia, J., Fitzgerald, K. A., O'Dell, M. W., Mastrogiovanni, A. R., \& Lin, C. D. (2011). The Mini-Mental State Examination and Montreal Cognitive Assessment in persons with mild subacute stroke: relationship to functional outcome. Arch Phys Med Rehabil, 92(5), 792798. doi:10.1016/j.apmr.2010.12.034

Wetter, S., Poole, J. L., \& Haaland, K. Y. (2005). Functional implications of ipsilesional motor deficits after unilateral stroke. Archives of Physical Medicine and Rehabilitation, 86(4), 776-781.doi: 10.1016/j.apmr.2004.08.009

Zhang, L., Han, X., Li, P., Liu, Y., Zhu, Y., Zou, J., \& Yu, Z. (2015). A study of tapping by the unaffected finger of patients presenting with central and peripheral nerve damage. Frontiers in human neuroscience, 9, 260.doi: 10.3389/fnhum.2015.00260

Zhu, H., McGrath, C., McMillan, A., \& Li, L. (2008). Can caregivers be used in assessing oral health-related quality of life among patients hospitalized for acute medical conditions? Community dentistry and oral epidemiology, 36(1), 27-33.doi: 10.1111/j.16000528.2006.00370.x 
Table 1

Criteria for Classifying Debris/ Calculus

\begin{tabular}{cl}
\hline Score & \multicolumn{1}{c}{ Criteria } \\
$\mathbf{0}$ & No debris/calculus present \\
$\mathbf{1}$ & Debris/calculus covering $<1 / 3$ of tooth surface \\
$\mathbf{2}$ & Debris/calculus covering $\geq 1 / 3$ and $<2 / 3$ of tooth surface \\
$\mathbf{3}$ & Debris/calculus covering $\geq 2 / 3$ of tooth surface \\
\hline
\end{tabular}

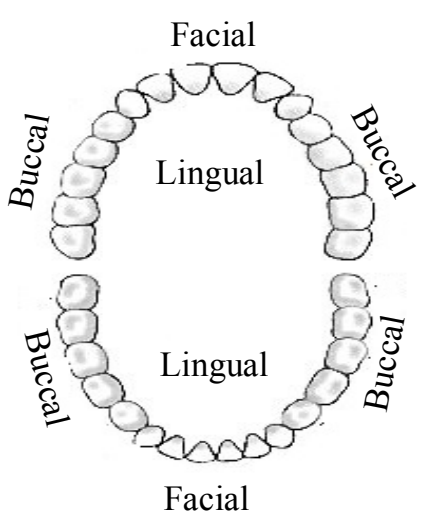

Figure 2. Tooth surfaces; buccal, lingual, and facial. Adapted from Root-CanalInfo.com. Copyright $(C$ [2006-2010] by Rooth-Canal-Info.com

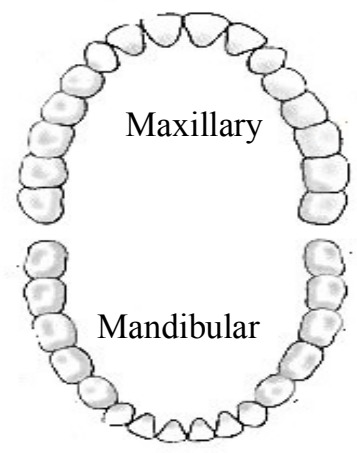

Figure 1. Dental arches; maxillary and mandibular. Adapted from RootCanal-Info.com. Copyright(C) [20062010] by Rooth-Canal-Info.com 
Table 2

Comparison of JHFT Subtest Mean Scores Between Our Sample and Norms

\begin{tabular}{llllll}
\hline & \multicolumn{2}{c}{$\begin{array}{c}\text { People without } \\
\text { stroke/norms }\end{array}$} & \multicolumn{3}{c}{$\begin{array}{c}\text { People with } \\
\text { stroke/our sample }\end{array}$} \\
\hline & Mean & SD & Mean & SD & Sig $(p)$ \\
\hline Card turning & 5.62 & 1.84 & 18.73 & 12.14 & 0.008 \\
Picking up small & 6.73 & 1.31 & 6.17 & 1.38 & 0.23 \\
common objects & & & & & \\
Stacking checkers & 8.05 & 1.38 & 8.97 & 1.52 & 0.09 \\
Simulated feeding & 5.21 & 1.47 & 9.42 & 5.97 & 0.05 \\
Moving light objects & 4.01 & 0.74 & 4.27 & 0.85 & 0.36 \\
Moving heavy objects & 4.04 & 0.76 & 4.69 & 0.91 & 0.05 \\
\hline
\end{tabular}


Table 3

Summary Statistics and Correlations Between Sensorimotor Tests and Change of OHI Score

\begin{tabular}{lcccc}
\hline Variable & Mean & $\begin{array}{c}\text { Standard } \\
\text { deviation } \\
(\mathrm{SD})\end{array}$ & $\begin{array}{c}\text { Correlation with } \\
\text { OHI change score } \\
\left(\mathrm{r}_{\mathrm{s}}\right)\end{array}$ & $\begin{array}{c}\text { Sig } \\
(p)\end{array}$ \\
\hline FMA & 47.10 & 22.66 & .43 & .26 \\
JHFT & 52.24 & 18.26 & -.43 & .24 \\
Nine-hole peg & 26.61 & 2.76 & -.27 & .49 \\
Grip Strength & 51.53 & 24.24 & .09 & .81 \\
Tapping test & 43.84 & 6.65 & .19 & .62 \\
& & & \\
\hline $\begin{array}{l}\text { Note. JHFT }=\text { Jebsen Hand Function Test; FMA= Fugl-Meyer Motor } \\
\text { Assessment }\end{array}$
\end{tabular}




\section{Appendix C: Comprehensive Examination Two}

Exploring Relationships between Fatigue, Motor Changes and Sensory Processing After Stroke 


\begin{abstract}
The purpose of this study was to explore sensory processing patterns for individuals after stroke and how it related to perceived level of fatigue, and motor abilities. We recruited eight stroke survivors living in the community at least one-year post stroke. Outcome measures included the Adolescent/Adult Sensory profile, Fugl-Meyer Assessment, and the Fatigue Short Form Questionnaire from the Neuro-QOL measures. Spearman's rank correlation showed no correlation between the level of fatigue perception and motor function. Although we found no significant correlation between FSFQ total score and sensory patterns, we did find a significant correlation at the items level score (e.g. correlation between Seeking pattern and question six "I was frustrated by being too tired to do the things I wanted to do" $\left.\left(r_{s}=-0.80, p=0.02\right)\right)$. It is proposed that Adult sensory profile may be a valuable part of a stroke recovery assessments to improve insight about sensory patterns.
\end{abstract}

Keywords: sensory processing, fatigue, stroke 


\section{Introduction}

Sensory processing is a construct that refers to the ability of the nervous system to receive and respond to the internal and external sensory information (Dunn, 1997). The nervous system integrates these stimuli to map a person's experience within different environments. Sensory systems affect cognitive and behavioral functions, which could affect a person's life experience. Changes in sensory systems and sensory processing could lead to further changes in cognitive and behavioral functions (Chung \& Song, 2016).

Stroke is one of the most common neurological conditions experienced by adults in the United States (Roger et al., 2012). Changes in motor, sensory, and/or cognitive abilities are common after stroke, and these changes influence functional performance and quality of life (Desrosiers et al., 2003). Although sensory changes are common after stroke (Connell, 2008) and they are related to motor changes (Campfens et al., 2015; Schabrun \& Hillier, 2009), rehabilitation strategies tend to focus attention on motor changes and neglect addressing sensory changes. Individuals may experience changes in awareness to environmental stimuli (their ability to perceive sensory information from inside and outside the body) which affects functional performance and quality of life (Schabrun \& Hillier, 2009). For example, postural control is important for functional activities such as mobility which is highly dependent on the awareness and integration of visual, proprioception, and vestibular information. Shumway-Cook and Woollacott (2000) suggest that changes in environmental sensory stimuli could affect postural control. Table 1 highlights examples regarding motor changes and its sensory components, and possible intervention strategies directed toward the sensory components. $<$ Place Table 1 about here $>$ 
Fatigue after stroke is a complex phenomenon that is poorly understood in research due to its subjective definition (Parks et al., 2012). De Groot et al. (2003) defined fatigue in neurological diseases as "a feeling of physical tiredness and lack of energy that is described as pathological, abnormal, excessive, chronic, persistent or problematic" (p.1715). The prevalence of fatigue among the stroke population is higher than people without stroke (Egerton et al., 2015). Thirty-nine to seventy-two percent of stroke survivors reported fatigue as one of the main factors affecting participation and completion of activities of daily life (Colloe et al., 2006). Fatigue among stroke survivors was associated with depression, anxiety (Snaphaan, Van Der Werf, \& de Leeuw, 2011), poor functional outcome, low quality of life (van de Port et al., 2007), and could also lead to social life withdrawal (Flinn \& Stube, 2010). Previous research also found fatigue to be correlated with higher dependency in activities of daily living (Carlsson, Moller, \& Blomstrand, 2008), longer hospitalization (Morley, Jackson, \& Mead, 2005), and lower rate of participation in rehabilitation after stroke (Glader, Stegmayr, \& Asplund, 2002). Stroke survivors reported that they have started experiencing fatigue at the time of stroke. They also mentioned exercise, good sleep, rehabilitation and rest as factors to reduce fatigue (Barbour \& Mead, 2011). Some researchers consider fatigue an internal sensory cue. Gijsbers van Wijk and Kolk (1997) reported that the way people experience external sensory stimuli could affect their experience of fatigue. Too many or too few external sensory stimuli can lead to feeling overwhelmed or bored, which may trigger fatigue. Exertion fatigue can result from the physical effort (e.g. household chores, exercises), or mental effort (e.g. play puzzle, or remember something that is hard to remember) needed to accomplish daily tasks. Pathologic fatigue is associated with a disease, is chronic in nature and usually remains regardless the physical or mental effort exerted (Tseng et al., 2010). People with stroke identify environmental conditions, 
such as noise and crowds, as main factors contributing to their experience of fatigue (Barbour \& Mead, 2011). The environment is rich with sensory stimuli that could play a role in fatigue perception, especially if the nervous system finds these external stimuli as too many or too few to be processed. Colbeck (2016) studied the relationship between fatigue and sensory processing among people with Multiple Sclerosis (MS). Colbeck reported the importance of including sensory processing to the MS evaluation toolbox. Different sensory processing patterns were found to be correlated with the fatigue perception among MS population. Such evidence is limited among stroke population.

Dunn's sensory processing framework suggests variations in behavioral responses to sensory information are derived from differences in a person's neurological thresholds (2014). People with high thresholds need more sensory input to respond to sensory stimuli, while people with low thresholds notice sensory stimuli very easily and are sensitive to environmental stimulation. Individuals may either actively control the amount of the sensory input they experience (i.e. active self-regulation) or let the sensory stimuli happen then react (i.e. passive self-regulation; Dunn, 2007). Depending on various combinations of neurological thresholds and self-regulatory behavioral responses, four different sensory patterns have been established for how people experience their sensory environments (Dunn, 2014). Individuals with high neurological thresholds experience a low registering or sensory seeking pattern. People with registration pattern respond slowly to sensory stimuli since they fail to detect sensory inputs as other people do. People with seeking pattern seek out sensory stimulations from the environment and enjoy experience sensory-rich activities. Conversely, individuals with low neurological thresholds experience sensory sensitivity or sensation avoiding patterns (Brown et al., 2001). People with sensitivity pattern are easily distracted from environmental sensory stimulations, but 
they did not tend to avoid these undesirable stimulations. People with avoiding pattern avoid sensory stimulations by limiting the sensory inputs to their nervous system. Literature suggests a person's sensory processing patterns impact behaviors and personality traits (Dunn, 2001) and social behaviors (Dunn, 1997) and affect (Engel-Yeger, and Dunn, 2011).

Sensory patterns tend to be the same across lifespan, however, sensory maps created in the brain could be changed throughout life due to exposure to different environmental stimuli and participation in different activities Dunn (2001). This study will explore sensory processing patterns for individuals after stroke and its relationship with fatigue perception and motor skills. This may offer a novel and important means of assisting stroke survivors to return to regular activities and attain a higher quality of life.

\section{Research questions and Hypotheses}

1. Do people who have experienced stroke have different intensity of sensory patterns compared with the normative sample?

We hypothesize that adults who have had a stroke have different intensity of sensory patterns compared with norming sample.

2. What are the relationships between sensory patterns, motor changes, and fatigue perception post stroke?

a. We hypothesize that there will be relationships between sensory processing patterns, motor changes, and fatigue perception post stroke.

b. We hypothesize that fatigue is positively correlated with sensory processing patterns associated with a low neurological threshold (that is; sensory sensitivity and sensory avoiding). 


\section{Methods}

\section{Participants}

Eligible subjects were stroke survivors 18 years of age or older and living in the community at least one year post stroke. Researchers recruited participants from a communitybased program in a large Midwestern city. To ensure participants understood and could respond to basic interview questions and study questionnaires, we only included participants who scored 26 or higher on the Montreal Cognitive Assessment (MoCA) and excluded participants who had a receptive aphasia diagnosis (based on medical records). We also excluded participants who had history of other central nervous system diseases (e.g., Traumatic Brain Injury) or had been diagnosed with dementia.

\section{Measures}

The Montreal Cognitive Assessment (MoCA; Nasreddine et al., 2005). MoCA is a screening tool used to detect mild cognitive dysfunction in adults. The MoCA is a 30-point scale divided into 7 cognitive subtests: visuo-executive, naming, attention, language, abstraction, delayed recall, and orientation. The MoCA demonstrates excellent internal consistency $($ Chronbach's alpha $=0.78)$ and correlation with other cognitive assessments $(\mathrm{MMSE}, \mathrm{r}=0.79$; FIM, $r=0.67)$. The exclusion criteria for participation is a score of $<20$, recommended as the cutoff value to protect against enrolling participants who have difficulty comprehending simple instructions (Chiti and Pantoni, 2014).

Adolescent/Adult Sensory profile (AASP; Brown \& Dunn, 2002). This is a self-report measure of person's response to sensory lived experience. Individuals respond to a 5-point Likert scale (almost always to almost never) to describe the frequency of behaviors in each sensory experience. Sixty items of this measure are organized among the four categories of sensory 
patterns corresponding to Dunn's Sensory Processing Framework: Low registration, Sensation seeking, Sensation avoiding, and Sensory sensitivity. AASP has good internal consistency for adults and older adults (.692 for Low Registration, .639 for Sensation Seeking, .657 for Sensory Sensitivity, and .699 for Sensation Avoiding; Brown \& Dunn,2002). Previous research showed that people after stroke had validly filled out the sensory profile (Chung \& Song, 2016).

Fugl-Meyer Assessment (FMA; Fugl-Meyer et al., 1975). The FMA is a widely-used assessment measure to evaluate movement ability after stroke (Gladstone et al, 2002) including upper extremity (UE) function, lower extremity function, balance, sensation, position sense, range of motion, and joint pain. Each section can be scored separately, and we will assess the affected arm to evaluate UE function after stroke. The FMA is valid and sensitive to detect UE function after stroke and shows excellent interrater reliability $(r=0.98-0.995$; Duncan et al, 1983).

The Fatigue Short Form Questionnaire (FSFQ, Cella et al., 2012) is one of the thirteen quality of life (QOL) measures within the Neuro-QOL. From these thirteen self-reported QOL measures, the researchers found all measures were reported as reliable (Cella et al., 2012). The FSFQ asks eight questions about feelings of fatigue and how it affects their ability to engage in occupations. The response for each question is ranging from 1 to 5 . A total score was calculated by summing the value for each question. The higher the score the higher the fatigue the individual experiences.

\section{Procedures}

The study utilized cross sectional study design approved by the University IRB. Researchers administered MoCA and reviewed participant's charts to determine eligibility to participate in the study. Then they obtained written informed consent from each participant who 
agreed to participate in the study. Two evaluators administer the series of behavioral assessments, in addition to a demographic questionnaire, while participants in a seated position. Total testing time for the behavioral assessments took approximately 1-1/2 hours. Assessments were completed at the community-based program over two months.

\section{Data Analysis}

We used IBM: SPSS (v. 23) to perform statistical analyses. All statistical tests of hypotheses employed a level of significance of alpha $=0.05$. A one sample t-test examined if there were significant difference between the mean of our sample in of each the sensory patterns of the AASP and the established mean of sensory pattern in the literature for people without stroke. Spearman's rank correlation examined the relation of sensory processing patterns and the scores of other assessment measures.

Since we have small sample size, AASP categories ('Much less than most people'; 'Less than most people'; 'Similar to most people'; 'More than most people' and 'Much more than most people') were collapsed into three categories (less than most people, similar to most people, more than most people) which yielded to higher number of responses in each category (EngelYeger \& Dunn, 2011). We used descriptive analysis to examine demographic information and frequency of responses within categories in each sensory pattern.

\section{Results}

Eight participants $(M=63, S D=6$ years), 4 males and 4 females met eligibility criteria to participate in the study. All participants reported race as Caucasian. Four participants experienced ischemic stroke, and four of them experienced hemorrhagic stroke. The average years post stroke was six years $(M=6, S D=5)$. Descriptive statistics indicated that the average score for the Registration pattern was $(M=36.8, S D=9.3)$, for the Seeking pattern $(M=49.6$, 
$S D=9.0)$, for Sensitivity pattern $(M=34.6, S D=6.9)$, and $(M=33.4, S D=7.0)$ for Avoiding pattern. In reviewing sensory pattern descriptive statistics in Table 2, there were no significant differences between study participants and normative sample regarding the averages score of sensory processing patterns. Figure 1 illustrates the frequency of behaviors in AASP categories for each sensory pattern. While fifty percent of participants appeared to have similar intensity of sensory patterns compared to the norming sample, twenty five percent of participants responded with fewer seeking responses than average.

$<$ Place Table 2 about here $>$

$<$ Place Figure 1 about here $>$

Although we didn't find a significant correlation between total score of perceived level of fatigue and sensory processing patterns, we found multiple correlations between specific items of FSFQ and sensory processing patterns (see Table 3). We found a strong negative correlation between seeking pattern and item five "I was too tired to leave the house" of FSFQ $\left(r_{s}=-0.75, p\right.$ $=0.03)$. We also found a strong negative correlation between seeking pattern and item six "I was frustrated by being too tired to do the things I wanted to do" of FSFQ $\left(r_{s}=-0.80, p=0.02\right)$. There was a strong correlation between avoiding pattern and item five "I was too tired to leave the house "of FSFQ $\left(r_{s}=0.79, p=0.02\right)$. Item two of FSFQ "I felt that I had no energy" was strongly correlated with avoiding pattern $\left(r_{s}=0.75, p=0.03\right)$. Question three of FSFQ "I felt fatigued" was strongly correlated with sensitivity pattern $\left(r_{s}=0.82, p=0.01\right)$.

$<$ Place Table 3 about here $>$

Regarding the correlation with motor function, we found no significant correlation between motor abilities and sensory processing patterns. We also found no significant correlation 
between the level of fatigue perception and motor function; neither for the total fatigue score, nor for the FSFQ item level score (see Table 3).

\section{Discussion}

This study investigated the relationship between sensory processing, fatigue, and motor skills. Sensory processing describes a person's response to internal and external sensory information. This construct has been studied extensively in other neurological conditions, such as autism. However, few studies have sought to study the sensory processing patterns in people with stroke despite qualitative evidence that changes in sensory processing may be a limiting factor in people's daily life (Carlsson, Moller \& Blomstrand, 2009). The study findings showed that people after stroke exhibited similar sensory patterns as those exhibited by the norming sample.

Some people after stroke demonstrated changes in individual sensory systems (such as touch and proprioception, Carey, 1995)); therefore, we hypothesized that sensory processing patterns might also change. Since we don't have the data regarding individual's sensory patterns before stroke, we hypothesized that the frequency of sensory responses (indicated through scores for the sensory patterns) for people with stroke would be different from the norming sample. Our findings showed no significant differences between sensory processing patterns among stroke survivors and the norming sample of people without stroke. These results are in line with most of the reported data from the Sensory Profile literature that sensory patterns remain the same across time (Dunn,2001).

In another study, researchers found that sixty-seven percent of the stroke population reported similar intensity of sensory patterns reported by non-stroke population (Chung and Song, 2016). Sensory processing involves organizing more than one sensory modality. Pohl et al 
(2016) highlighted that there is a difference in evaluating acuity and evaluating sensory processing patterns, since changes in acuity don't necessarily mean changes in sensory processing patterns overall (Dunn, 2001). For instance, a person who registers sensory input faster than others (low sensory threshold pattern) may be more likely to notice the temperature of a cup of coffee compared to a person who has a registration (high threshold) sensory pattern. If a stroke reduces the person with a low threshold's touch acuity, there is a higher likelihood that this person needs more input to notice the cup temperature compared to himself before stroke (maybe he will start acting like an individual who has a registration pattern in terms of touch sensation). However, he may still be as sensitive to sound (auditory) or light (visual) as he was before the stroke. Therefore, evaluating the person's sensory acuity changes after stroke as well as gathering information regarding sensory processing pattern using the AASP will provide the best understanding of sensory profile after stroke.

Twenty five percent participants responded with fewer seeking responses than average. One explanation is that people after stroke may experience sensory changes, such as with touch responsiveness, which may decrease the actual sensory input. Moreover, Pohl, Dunn and Brown (2003) found that older people in the general population sought less sensory inputs compared with the younger people which may explain why our study participants also exhibited less engagement than most people in sensation seeking behavior. Perhaps seeking less input is related to being an older adult rather than to having a stroke.

Chung and Song (2016) also mentioned that people with stroke may have difficulty pursuing environmental stimuli to meet their high neurological threshold. For example, a person who had a stroke with associated motor and sensory changes may find it hard to participate in outside activities (e.g., restaurants, concerts), reducing exposure to external environmental 
stimuli. Also, environmental barriers, such as inaccessible public toilets, may limit ability to reintegrate in activities that meet their neurological threshold (Urimubenshi \& Rhoda, 2001). For instance, a person who is a seeker and used to seek sensation through participating in outdoor social activities, will have difficulty seeking the same sensation after a stroke if the environment is not accessible. These results invite health care professionals in general, and occupational therapy specifically, to understand the influence of sensory patterns on different aspects of daily life activities. For instance, an occupational therapist working with a stroke survivor who has a registration pattern, may provide a video with exercise demonstration in addition to the usual exercise verbal instructions to help the client do the exercise correctly. In the latter example, the person may show better understanding of the exercises as additional stimulation (i.e. vision) was added to the usual hearing stimulation (i.e. verbal instructions). Therapists also will be able to recommend therapeutic activities based on the client's sensory preference. For example, a client who is a seeker prefers to participate in activities with rich sensation (e.g. climbing, dancing). An individual who has a sensitive pattern may perform better in therapeutic activities if the environment has little distractions since he/she is easily distracted by environmental stimuli.

\section{Correlations between Sensory Processing patterns, fatigue, and motor skills}

In this study, we aimed to understand the contribution of sensory processing patterns in fatigue perception after stroke. Colbeck (2016) aimed to understand the contribution of sensory processing in fatigue perception among thirty people with MS. Colbeck (2016) found that low threshold sensory processing patterns (i.e., sensitivity and avoiding) correlate with cognitive fatigue and should be considered when evaluating fatigue among MS population.

In the present study, sensory patterns did not correlate with overall fatigue score of FSFQ. However, sensory processing patterns were correlated strongly with activity-based related 
questions of FSFQ; for example, seeking pattern was negatively correlated with question five "I was too tired to leave the house". It is possible that people who feel less fatigued leave the house more often, which supports engagement in more sensation seeking behaviors. Conversely, this finding could demonstrate that people who seek sensory input find ways to leave the house to get the input they need, regardless of fatigue. The results also showed that the less people felt frustrated or tired carrying out daily activities, the more they engaged in sensation seeking behaviors. Or in other terms, a person who is a seeker feels less fatigued participating in daily activities.

Particular fatigue items were correlated with Sensitivity and Avoiding patterns as we hypothesized. These two patterns are low threshold patterns, which means people have high ability to notice environmental stimuli. The results indicated that people who are distracted or overwhelmed by environmental stimuli feel more fatigued and have no energy. Maybe people with low threshold patterns are overloaded with external sensory cues and feel overwhelmed, which directed their attention to internal cues (i.e., fatigue). For example, a person who has Sensitivity pattern, who notices stimuli more easily than others, visits a movie theater and becomes distracted by the crowds, movement and sounds. This may cause them to feel fatigued and tired throughout the activity or when they get home.

Our findings indicate that there is no correlation between motor abilities (measured by FMA) and perceived level of fatigue. This may suggest that the level of motor impairment caused by stroke does not necessarily play a role in the perceived level of fatigue. These findings support previous research that suggested no correlation between physical function (Ponchel et al., 2015) and motor activity and inactivity with fatigue (Egerton et al., 2015). These results are consistent with literature showing fatigue after stroke is not exclusively a physical fatigue instead 
it a multifaceted phenomenon (Parks et al., 2012). Muina and Guidon (2013) reported that activity related fatigue and mental fatigue were the most common types of fatigue after stroke. In our study, we tested the general fatigue which may explain the absence of correlation between fatigue and physical abilities.

According to Dunn's framework (2014), a person exhibits specific sensory patterns as he/she uses passive or active behavioral strategies in responding to neurological threshold. Motor changes play a role in people's participation in daily life activities since these changes affect their mobility and ability to react to environmental stimuli (Hunter,2002). So, we anticipated that strategies of self-regulation in reacting to environmental stimuli (passive $v s$ active) correlate with motor ability. For example, people with less motor changes have sensory patterns of active selfregulation behaviors (i.e. Sensation seeking and Sensation avoiding). Contrary to our hypothesis, there was no relationship between sensory processing patterns and movement abilities after stroke. We postulate that perhaps people after stroke develop coping strategies that match their sensory preferences to cope with environments. This highlights the importance of orienting individuals to their sensory preferences and help them to develop coping strategies and select activities that match their sensory patterns.

\section{Conclusion}

Study findings reveal the possible influence sensory processing has on fatigue perception. The Adult Sensory Profile can be a valuable contribution to stroke recovery assessments to improve an individualized rehabilitation plan. By improving people's insight about their sensory patterns, they will be able to use strategies that match their patterns to manage their environment and improve participation in daily activities. Furthermore, this information can increase the understanding of the individual's family members, friends, and coworkers regarding the 
individual's behaviors and responses to stimuli. Moreover, therapists could improve designing effective interventions that consider different aspects of individual's lived experience. 


\section{References}

Barbour, V. L., \& Mead, G. E. (2012). Fatigue after stroke: the patient's perspective. Stroke research and treatment, 2012. doi:10.1155/2012/863031

Brown, C., \& Dunn, W. (2002). The Adolescent/Adult Sensory Profile: User's manual. San Antonio, TX: The Psychological Corporation.

Brown, C., Tollefson, N., Dunn, W., Cromwell, R., \& Filion, D. (2001). The Adult Sensory Profile: Measuring patterns of sensory processing. American Journal of Occupational Therapy, 55,75-82.

Campfens, S. F., Zandvliet, S. B., Meskers, C. G. M., Schouten, A. C., van Putten, M. J. A. M., \& van der Kooij, H. (2015). Poor motor function is associated with reduced sensory processing after stroke. Experimental Brain Research, 233(4), 1339-1349. https://doi.org/10.1007/s00221-015-4206-z

Carey, L. M. (1995). Somatosensory loss after stroke. Critical Reviews ${ }^{\mathrm{TM}}$ in Physical and Rehabilitation Medicine, 7(1). doi:10.1615/CritRevPhysRehabilMed.v7.i1.40.

Carlsson, G., Möller, A., \& Blomstrand, C. (2004). A qualitative study of the consequences of'hidden dysfunctions' one year after a mild stroke in persons $<75$ years. Disability and rehabilitation, 26(23), 1373-1380.

Carlsson, G. E., Möller, A., \& Blomstrand, C. (2009). Managing an everyday life of uncertaintya qualitative study of coping in persons with mild stroke. Disability and rehabilitation, 31(10), 773-782.

Cella, D., Lai, J. S., Nowinski, C. J., Victorson, D., Peterman, A., Miller, D., ... \& Reder, A. T. (2012). Neuro-QOL Brief measures of health-related quality of life for clinical research in neurology. Neurology, 78(23), 1860-1867. doi: 10.1212/WNL.0b013e318258f744 
Chiti, G., \& Pantoni, L. (2014). Use of Montreal Cognitive Assessment in patients with stroke. Stroke, 45(10), 3135-3140. doi: 10.1161/STROKEAHA.114.004590

Chung, S. M., \& Song, B. K. (2016). Evaluation of sensory processing abilities following stroke using the adolescent/adult sensory profile: Implications for individualized intervention. Journal of Physical Therapy Science, 28(10), 2852-2856.

https://doi.org/10.1589/jpts.28.2852

Colle, F., Bonan, I., Leman, M. G., Bradai, N., \& Yelnik, A. (2006). Fatigue after stroke. In Annales de réadaptation et de médecine physique, 49(6), 361-364. https://doi.org/10.1016/j.annrmp.2006.04.010

Colbeck, M.A. Sensory Processing, Fatigue and Quality of Life for Adults with Multiple Sclerosis. Poster presented at: 2016 CMSC annual meeting; 2016 Jun 3; National Harbour, MD.

Connell, L. (2008). Somatosensory impairment after stroke: frequency of different deficits and their recovery. Clinical Rehabilitation, 22, 758-767. https://doi.org/10.1177/0269215508090674

de Groot, M. H., Phillips, S. J., \& Eskes, G. A. (2003). Fatigue associated with stroke and other neurologic conditions: implications for stroke rehabilitation. Archives of physical medicine and rehabilitation, 84(11), 1714-1720. https://doi.org/10.1053/S00039993(03)00346-0

Desrosiers, J., Malouin, F., Bourbonnais, D., Richards, C. L., Rochette, A., \& Bravo, G. (2003). Arm and leg impairments and disabilities after stroke rehabilitation: relation to handicap. Clinical Rehabilitation, 17(6), 666-673. 
Dunn, W. (1997). The impact of sensory processing abilities on the daily lives of young children and their families: A conceptual model. Infants and Young Children, 9(4), 23-25.

Dunn, W. (2001). The sensations of everyday life: Empirical, theoretical, and pragmatic considerations. American Journal of Occupational Therapy, 55(6), 608-620.

Dunn, W. (2007). Supporting children to participate successfully in everyday life by using sensory processing knowledge. Infants and Young Children, 20(2), 84-101.

Egerton, T., Hokstad, A., Askim, T., Bernhardt, J., \& Indredavik, B. (2015). Prevalence of fatigue in patients 3 months after stroke and association with early motor activity: a prospective study comparing stroke patients with a matched general population cohort. BMC neurology, 15(1), 181. doi: 10.1186/s12883-015-0438-6

Engel-Yeger, B., \& Dunn, W. (2011). Exploring the relationship between affect and sensory processing patterns in adults. British Journal of Occupational Therapy, 74(10), 456-464. Doi:' $10.4276 / 030802211 X 13182481841868$

Flinn, N. A., \& Stube, J. E. (2010). Post-stroke fatigue: qualitative study of three focus groups. Occupational therapy international, 17(2), 81-91. Doi: 10.1002/oti.286

Friedman, J. H., \& Friedman, H. (2001). Fatigue in Parkinson's disease: a nine-year followup. Movement disorders, 16(6), 1120-1122. doi:10.1002/mds.1201

Fugl-Meyer, A. R., Jaaskc, L., Layman, I., Olsson, S., \& Stcglind, S. (1975). THE POSTSTROKE HEMIPLEGIC PATIENT. Scand J Rehab Med, 7(13), 31.

Gijsbers van Wijk, C. M., \& Kolk, A. M. (1997). Sex differences in perceived health. Nederlands tijdschrift voor geneeskunde, 141(6), 283-287.

Glader, E. L., Stegmayr, B., \& Asplund, K. (2002). Poststroke fatigue. Stroke, 33(5), 1327-1333. https://doi.org/10.1161/01.STR.0000014248.28711.D6 
Gladstone, D. J., Danells, C. J., \& Black, S. E. (2002). The Fugl-Meyer assessment of motor recovery after stroke: A critical review of its measurement properties. Neurorehabilitation and Neural Repair ,16(3), 232-240. doi:10.1177/154596802401105171

Hunter, J. V. (2002). Magnetic resonance imaging in pediatric stroke. Topics in Magnetic Resonance Imaging, 13(1), 23-38. doi: 10.1097/00002142-200202000-00003

Morley, W., Jackson, K., \& Mead, G. E. (2005). Post-stroke fatigue: an important yet neglected symptom. Age and ageing, 34(3), 313-313. doi:10.1093/ageing/afi082

Muina-Lopez, R., \& Guidon, M. (2013). Impact of post-stroke fatigue on self-efficacy and functional ability. European Journal of Physiotherapy, 15(2), 86-92. doi: $10.3109 / 21679169.2013 .792868$

Nasreddine, Z. S., Phillips, N. A., Bédirian, V., Charbonneau, S., Whitehead, V., Collin, I., ... \& Chertkow, H. (2005). The Montreal Cognitive Assessment, MoCA: a brief screening tool for mild cognitive impairment. Journal of the American Geriatrics Society, 53(4), 695699. doi: 10.1111/j.1532-5415.2005.53221.x

Parks, N., Eskes, G., Gubitz, G., Reidy, Y., Christian, C., \& Phillips, S. (2012). Fatigue Impact Scale Demonstrates Greater Fatigue in Younger Stroke Survivors. Canadian Journal of Neurological Sciences / Journal Canadien Des Sciences Neurologiques, 39(5), 619-625. doi:10.1017/S0317167100015353

Pohl, P. S., Dunn, W., \& Brown, C. (2003). The role of sensory processing in the everyday lives of older adults. OTJR: Occupation, Participation and Health, 23(3), 99-106. 
Ponchel, A., Bombois, S., Bordet, R., \& Hénon, H. (2015). Factors associated with poststroke fatigue: a systematic review. Stroke research and treatment, 2015. http://dx.doi.org/10.1155/2015/347920

Roger, V. L., Go, A. S., Lloyd-Jones, D. M., Benjamin, E. J., Berry, J. D., Borden, W. B., ... \& Fullerton, H. J. (2012). Heart disease and stroke statistics—2012 update a report from the American heart association. Circulation, 125(1), e2-e220.

Schabrun, S. M., \& Hillier, S. (2009). Evidence for the retraining of sensation after stroke: a systematic review (Structured abstract). Clinical Rehabilitation, 23(1), 27-39. https://doi.org/10.1177/0269215508098897

Shumway-Cook, A., \& Woollacott, M. (2000). Attentional demands and postural control: the effect of sensory context. Journals of Gerontology Series A: Biological and Medical Sciences, 55(1), 10. https://doi.org/10.1093/gerona/55.1.M10

Snaphaan, L. J. A. E., Van Der Werf, S., \& de Leeuw, F. E. (2011). Time course and risk factors of post-stroke fatigue: a prospective cohort study. European Journal of Neurology, 18(4), 611-617. Doi: 10.1111/j.1468-1331.2010.03217.x

Tseng, B. Y., Billinger, S. A., Gajewski, B. J., \& Kluding, P. M. (2010). Exertion fatigue and chronic fatigue are two distinct constructs in people post-stroke. Stroke, 41(12), 29082912. https://doi.org/10.1161/STROKEAHA.110.596064

van de Port, I. G., Kwakkel, G., Schepers, V. P., Heinemans, C. T., \& Lindeman, E. (2007). Is fatigue an independent factor associated with activities of daily living, instrumental activities of daily living and health-related quality of life in chronic stroke? Cerebrovascular Diseases, 23(1), 40-45. 
Urimubenshi, G., \& Rhoda, A. (2011). Environmental barriers experienced by stroke patients in Musanze district in Rwanda: a descriptive qualitative study. African health sciences, 11(3). 


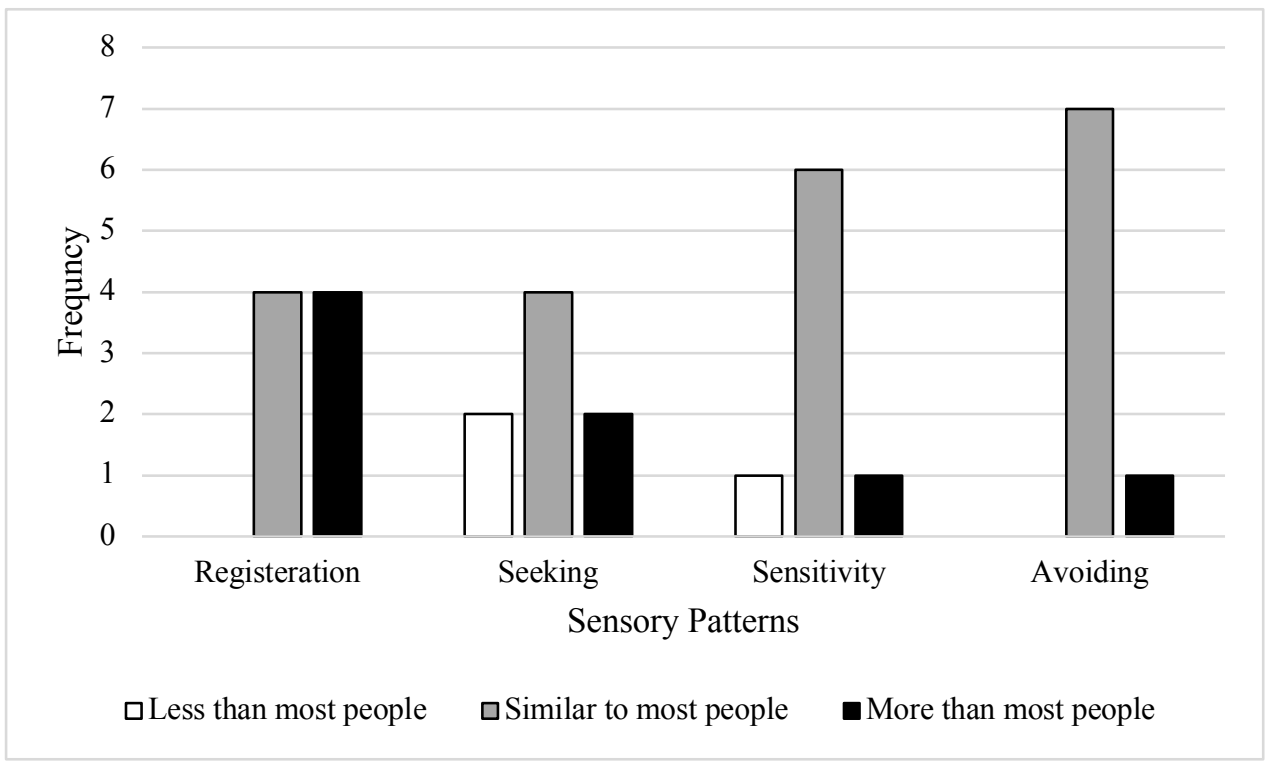

Figure 3. Frequency of Responses in Each Sensory Pattern 
Table 1

Motor Changes After Stroke: Sensory Components and Intervention Strategies

Motor changes Sensory Components

Intervention Strategies

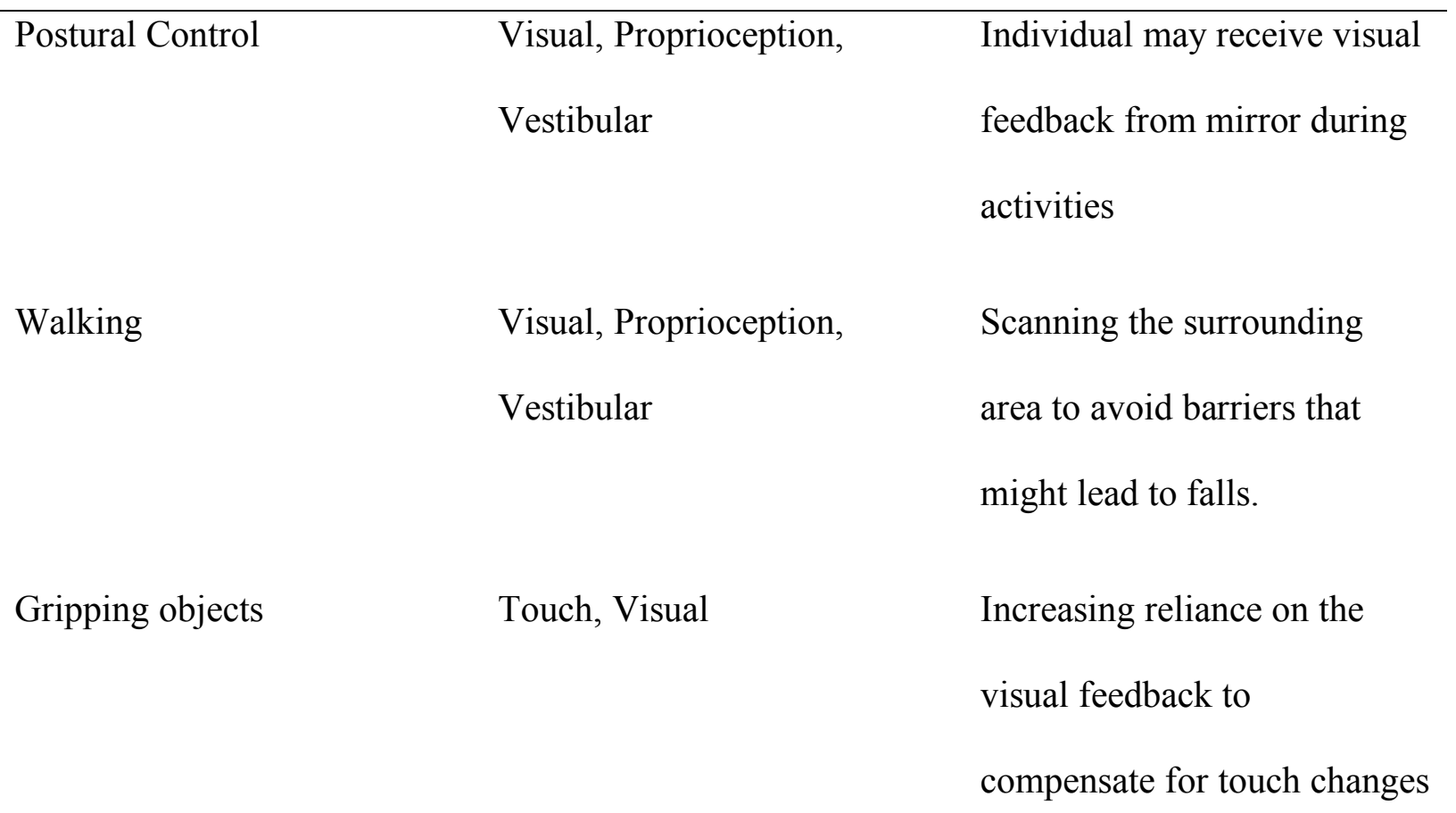


Table 2

Comparison of average scores for our study participants versus normative sample

\begin{tabular}{ccccc}
\hline & Registration & Seeking & Sensitivity & Avoiding \\
\hline Mean \pm SD & & & & \\
\hline Study participants & $36.75 \pm 9.30$ & $49.63 \pm 9.02$ & $34.63 \pm 6.98$ & $33.38 \pm 7.05$ \\
Norming sample & $30.29 \pm 6.25$ & $49.91 \pm 6.83$ & $33.71 \pm 7.63$ & $34.57 \pm 7.34$ \\
& & & & \\
\hline
\end{tabular}

Note. Mean \pm SD: Mean and standard deviation ${ }^{*} p<0.05$ 
Table 3

Correlation Statistics Between Fatigue Short Form Questionnaires (FSFQ), FMA, and Sensory Processing Patterns

\begin{tabular}{|c|c|c|c|c|c|}
\hline FSFQ items & $\begin{array}{c}\text { Registration } \\
r_{s}(p)\end{array}$ & $\begin{array}{l}\text { Seeking } \\
r_{s}(p)\end{array}$ & $\begin{array}{c}\text { Sensitivity } \\
r_{s}(p)\end{array}$ & $\begin{array}{c}\text { Avoiding } \\
r_{s}(p)\end{array}$ & $\begin{array}{l}\text { FMA } \\
r_{s}(p)\end{array}$ \\
\hline I felt fatigued & $.597(.118)$ & $\begin{array}{l}-.561 \\
(.148)\end{array}$ & $\begin{array}{l}.822^{*} \\
(.012)\end{array}$ & $.655(.078)$ & $\begin{array}{l}-.399 \\
(.328)\end{array}$ \\
\hline I felt exhausted & $.498(.209)$ & $\begin{array}{l}-.225 \\
(.592)\end{array}$ & $.605(.112)$ & $.620(.101)$ & $\begin{array}{l}.394 \\
(.334)\end{array}$ \\
\hline I felt that I had no energy & $.340(.410)$ & $\begin{array}{l}-.289 \\
(.488)\end{array}$ & $.507(.200)$ & $\begin{array}{l}.751^{*} \\
(.032)\end{array}$ & $\begin{array}{l}.091 \\
(.83)\end{array}$ \\
\hline $\begin{array}{l}\text { I was too tired to do my } \\
\text { household chores }\end{array}$ & $-.505(.202)$ & $\begin{array}{l}-.107 \\
(.801)\end{array}$ & $\begin{array}{l}-.274 \\
(.512)\end{array}$ & $\begin{array}{l}-.094 \\
(.826)\end{array}$ & $\begin{array}{l}.535 \\
(.172)\end{array}$ \\
\hline $\begin{array}{l}\text { I was too tired to leave the } \\
\text { house }\end{array}$ & $.391(.338)$ & $\begin{array}{l}-.747^{*} \\
(.033)\end{array}$ & $.655(.078)$ & $.785^{*}(.021)$ & $\begin{array}{l}.074 \\
(.862)\end{array}$ \\
\hline $\begin{array}{l}\text { I was frustrated by being too } \\
\text { tired to do the things I wanted } \\
\text { to do }\end{array}$ & $.063(.882)$ & $\begin{array}{l}-.795^{*} \\
(.018)\end{array}$ & $.501(.206)$ & $.487(.221)$ & $\begin{array}{l}-0.175 \\
(.678)\end{array}$ \\
\hline I felt tired & $-.510(.196)$ & $\begin{array}{l}-.404 \\
(.321)\end{array}$ & $\begin{array}{l}-.282 \\
(.499)\end{array}$ & $\begin{array}{l}-.289 \\
(.488)\end{array}$ & $\begin{array}{l}.169 \\
(.689)\end{array}$ \\
\hline $\begin{array}{l}\text { I had to limit my social } \\
\text { activity because I was tired }\end{array}$ & $-.466(.245)$ & $\begin{array}{l}-.462 \\
(.249)\end{array}$ & $\begin{array}{l}-.100 \\
(.814)\end{array}$ & $\begin{array}{l}-.051 \\
(.904)\end{array}$ & $\begin{array}{l}0.325 \\
(.432)\end{array}$ \\
\hline
\end{tabular}

Note. $\mathrm{r}_{s}=$ Spearman's correlation coefficient

$* p \leq .05$ 


\section{Appendix D: Comprehensive Examination Three}

The Relationship between Sensory Processing and Activity Participation Among CommunityDwelling Stroke Survivors 


\begin{abstract}
The purpose of this study was to examine the impact of sensory processing patterns on activity participation among community-dwelling stroke survivors. We used a mixed method design to collect information about the experience of people after stroke regarding sensory changes and its impact on their participation in daily life activities. We interviewed selected participants regarding their experiences with sensory changes after stroke and triangulated findings with two standardized measures: The Adolescent/Adult Sensory profile, and Activity Card Sort. While the data derived from the interviews focused on the sensitivity participants experienced after stroke, data derived from the standardized assessments showed the relationship between sensory patterns and retained daily activities. Participants reported using various coping strategies to adapt to sensitivity after stroke. The study findings indicated that sensory patterns may impact engagement in daily activities among people who have experienced a stroke.
\end{abstract}

Keywords: sensory processing, activity participation, stroke 


\section{Introduction}

Participation is "the involvement in a life situation" (WHO, 2001, p.10), and it is the main outcome of occupational therapy interventions (Occupational Therapy Practice Framework (3rd Edition), 2014). People engage in activities that provide a sense of competence and add purpose to life. According to the International Classification of Functioning, Disability and Health (ICF) framework, a disability or a disease may lead to impairments in body structures or body functions (WHO, 2001). For example, stroke survivors may experience sensory, motor and/or mental function changes. Individuals may be restricted from participation in daily activities because of these impairments. According to the ICF, person's functioning including participation "is an interaction or complex relationship between the health condition and contextual factors (i.e., environmental and personal factors)" (WHO, 2001, p. 17). Therefore, the stroke survivor's ability to reengage in daily activities is affected by body changes, and environmental factors (Bouffioulx, Arnould, \& Thonnard, 2011).

While most of the literature attributed motor and cognitive changes as the most common causes of activity limitation after stroke (Cawood, Visagie \& Mji, 2016), survivors reported sensory factors as additional causes to limit their participation in daily occupations (Doyle, Bennett, \& Dudgeon, 2014). Somatosensory changes in the hand, as well as sensitivity to light and sound were the main sensory barriers to activity participation reported by stroke survivors (Carlsson, Möller, \& Blomstrand, 2009). Proprioception was also found to be highly correlated with physical activity restrictions and social isolation (Meyer et al., 2014). Although most of the literature studied the impact of somatosensory changes on activity participation, the integration of all sensory system influences engagement in daily life (Meyer, et al., 2014; Engel-Yeger \& 
Rosenblum, 2016). After stroke, the ability to obtain and process information after these sensory changes impact participation in daily occupations (Doyle et al.,2014)

Sensory processing is described as the ability of the nervous system to manage environmental information to make sense of people's experiences. Dunn's sensory processing framework (2014), encompasses four patterns of sensory processing; Registration, Seeking, Sensitivity, and Avoiding. These patterns represent the combination of person's neurological threshold (i.e. reactivity), and responding or self-regulation strategies. High neurological threshold encompasses registration (i.e. passive self-regulation strategy) and seeking pattern (active self-regulation strategy). People with registration pattern usually miss environmental sensory stimuli or they respond slowly to sensation (e.g. less likely to notice the temperature of coffee when sipping it). Seeking pattern represents individuals who enjoy the rich sensory experiences (e.g. wearing heavy jewellery).

People with low neurological threshold experience either sensitivity (i.e. passive selfregulation) or avoiding pattern (i.e. active self-regulation). People with sensitivity notice and distracted easily from sensory stimuli compared to others (e.g. feeling uncomfortable from clothes tags or certain fabric texture). Finally, avoiding pattern represents individuals who avoid sensory stimuli (e.g. avoiding crowds, lights, sounds).

Patterns of sensory processing could impact the level of engagement in daily activities (Engel-Yeger \& Rosenblum, 2016). For example, older people with a seeking pattern participate at a higher level in daily occupations, while older people with an avoiding pattern engage less in activities especially the social activities (Engel-Yeger \& Rosenblum, 2016). Changes in sensory systems that happen with aging could impact the level of control the individual has over the environment which in turn influence participation in daily occupations (Pohl, Dunn \& Brown, 
2003). To our knowledge, little is understood about the impact of sensory processing patterns on activity participation after stroke. Therefore, the purpose of this study is to examine the impact of sensory processing patterns on activity participation among community dwelling stroke survivors.

\section{Research questions}

1. How is the level of engagement in 'leisure activity with high demand', 'leisure activity with low demand' 'social', and 'instrumental' activities (as measured by the Activity Card Sort) correlated with sensory processing patterns (as measured by the Adolescent Adult Sensory Profile).

2. How is the level of engagement in global activities (i.e. total current activity divided by the total previous activity; as measured by the Activity Card Sort) correlated with sensory processing patterns (as measured by the Adolescent Adult Sensory Profile).

3. What are stroke survivors' experience of sensory changes, and how they cope with these changes?

\section{Methods}

\section{Participants}

After receiving university Institutional Review Board approval, we recruited stroke survivors who are more than one year past their rehabilitation and participate in a community setting in a large Midwestern State. We included participants who scored 20 or higher on the Montreal Cognitive Assessment (MoCA) (based on the medical record), to ensure their ability to respond to the interview questions and understand the behavioral assessments. We excluded participants who had a receptive aphasia diagnosis as reported in the medical records. We also excluded participants with dementia and central nervous system diseases other than stroke such as Traumatic Brain injury. 
Eight participants ( 4 male, 4 female) completed the behavioral assessments, and three of these ( 1 male, 2 female) completed the interview. Participants ages ranged from 51 to 74 years $(M=62.8, S D=6)$. All participants reported race as Caucasian. Table 1 provides the participant demographic information.

$<$ table 1 inserted here $>$

\section{Measures}

Activity Card Sort (ACS; Baum \& Edwards, 2001). The ACS is an interview-based tool used to describe an individual's participation in different activities; instrumental activities of daily living (IADLs), low demand leisure activities (e.g., resting, reading for fun, crafting), high demand leisure activities (e.g., camping, biking, running), and social activities (e.g., attending church, visiting with family and friends). . Participants are asked to describe their level of engagement (i.e., 'continued to do after injury/illness', 'given up since injury/illness', 'beginning to do again since injury/illness', or 'never done')) in eighty-nine different activities shown on photo cards. The final score represents the percentage of activity retained since experiencing a stroke (i.e., the percentage of person's current engagement in activities compared to the level of engagement before the stroke). The ACS is a valid tool for use with people after stroke (Hartman-Maeir et al., 2007) and has excellent test-retest reliability (Chan, Chung, \& Packer, 2006).

Adolescent/Adult Sensory profile (AASP; Brown \& Dunn, 2002). This is a self-report measure of person's response to sensory lived experience. Individuals respond to a 5-point Likert scale (almost always to almost never) to describe the frequency of behaviors in each sensory experience. Sixty items of this measure are organized among the four categories of sensory patterns corresponding to Dunn's Sensory Processing Framework: low registration, sensation 
seeking, sensation avoiding, and sensory sensitivity. Brown et al (2001) supported the validity and internal reliability of the AASP. Previous research showed that people after a stroke had validly filled out the sensory profile (Chung \& Song, 2016).

Since we have small sample size, AASP categories ('Much less than most people'; 'Less than most people'; 'Similar to most people'; 'More than most people' and 'Much more than most people') were collapsed into three categories (less than most people, similar to most people, more than most people) which yielded to higher number of responses in each category (EngelYeger \& Dunn, 2011).

Individual Semi-Structured Interview. Researchers developed open-ended questions with probes to facilitate the interview. Researchers expert in sensory processing, and interprofessional group reviewed the prepared questions and provided suggestions and feedback. Based on these suggestions, we created a final version of the questions. For example, some of the questions asked were: What changes have you experienced in each sensory system? Explain how sensory changes affect your participation in social activities. How do sensory changes affect the tools that you use on daily? Additionally, we used a separate demographic form to collect demographic information and stroke-related information (such as stroke onset, side of stroke, and type of stroke) at the start of the interview.

\section{Research Design}

We used a mixed method design to collect information about the experience of people after stroke regarding sensory changes and its impact on their participation in daily life activities. To answer research question 1, we employed a descriptive design to explore the relationship between the sensory processing patterns and the type of activity people participate in. To answer research question 2, we employed inductive content analysis. 


\section{Procedure}

To address the first and the second research questions, we obtained informed consent, collected the demographic information and then participants completed the AASP and the ACS which took approximately an hour.

Following completion of the first part of the study, we asked if the participants were interested in completing the semi-structured interview (to address research question three). We reviewed the consent form document with those who agreed to participate in the second part of the study. After the participants consented, we completed the semi-structured interview which took approximately 45 minutes. The interview started with broad questions and was followed with further deeper questions for clarifications. The first author carried out, audio recorded and transcribed all the interviews.

\section{Data Analysis}

To answer research question 1 and 2, we used IBM: SPSS (v. 23) to perform statistical analyses. All statistical tests of hypotheses employed a level of significance of alpha= 0.05 . Spearman's rank correlation examined the relation of sensory processing patterns and the ACS results. Spearman's rank correlation is a nonparametric analysis that is appropriate for small sample sizes. We used descriptive statistics to examine participant demographic information.

To answer research question 3, we used the inductive content analysis approach to explore the qualitative data gathered in the second part of the study. The first author read the interview transcripts several times to identify possible meanings of each segment of the text. Then she coded each segment of the transcript to provide a possible set of codes and grouped similar codes into categories and developed definitions of the categories. 
Consistency checks with three researchers, other than the first author, were used to help establish dependability. Researchers did two rounds of establishing dependability. First, they used the definitions of the categories suggested by the first author to find the text segment which belongs to these categories. Researchers did the last procedure for the three transcripts then we compared the results and achieved $68 \%$ of agreement. After this comparison, we added examples and modified the definitions of the categories to make it clearer. Then researchers did another round of consistency checks to reach agreement level of (82\%). After we determined the reliability of the categories, we grouped similar categories into overarching themes.

To further establish trustworthiness we utilized field notes, reflective journaling before, during and after interviews, and peer debriefing during data collection and analysis. We also used flexible open-ended questions with probes to facilitate the discussion. We used data from both the behavioral assessments and interviews for participants who completed both parts of the study to produce credible findings and interpretations (i.e. triangulation).

\section{Results}

\section{Behavioral Assessments}

The average score for the Registration pattern was $(M=36.8, S D=9.3)$, for the Seeking pattern $(M=49.6, S D=9.0)$, for Sensitivity pattern $(M=34.6, S D=6.9)$, and $(M=33.4, S D=7.0)$ for Avoiding pattern. Table 2 demonstrates the correlation between the retained activities of daily life (according to ACS) and sensory patterns.

In comparing instrumental activities to sensory patterns, we identified two significant correlations. We found a significant strong positive correlation between sensation seeking and the percentage retained of instrumental activities $\left(r_{s}=0.90, p=0.002\right)$. For the registration pattern (i.e., miss more input), we found a significantly strong negative correlation with the 
percentage retained of instrumental activities $\left(r_{s}=-0.71, p=0.05\right)$ (i.e., the more the person misses sensory cues, the less the person retains instrumental activities).

$<$ Table 2 inserted here $>$

When considering sensory patterns and high demand activities we found a significantly strong negative correlation between percentage retained of high demand activities and the sensitivity pattern $\left(r_{s}=-0.74, p=0.04\right)$. In other words, participants who are less sensitive to sensory stimuli participated more in high demand activities after stroke compared to those who are more sensitive. However, data did not show significant correlations between retained low demand activities and sensory patterns.

When considering the correlation between social activities retained and sensory patterns, we found a moderate negative correlation, yet not significant, between sensitivity pattern and the percentage retained of social activity $\left(r_{s}=-0.64, p=0.08\right)$. Additionally, we found a significantly strong negative correlation between the percentage of the global activity retained (i.e. total current activity divided by the total previous activity) and sensitivity pattern $\left(r_{s}=-0.76, p=\right.$ 0.03). This means that persons with more sensitivity retain less total activities. We also found a negative trend between the avoiding pattern and the percentage of retained activities (i.e. social, instrumental, low and high demand activities).

\section{Individual Semi-Structured Interview}

The three participants who completed the interview showed sensory patterns that were similar to most people, with one exception. That is, the participants did not demonstrate one dominant sensory processing pattern with the exception of one participant who scored in the "More Than Others" range for the Registration pattern. 
As demonstrated in table 3, two themes and seven categories emerged from our data analysis. Although interview questions not exclusively addressed sensitivity as a sensory change after stroke; however, sensitivity was the most prominent theme arose during these interviews. $<$ table 3 inserted here $>$

Theme one: Changes in sensory perception after stroke. This theme focuses on participants' description of the sensory changes they experience after stroke. This theme includes two categories: Responsiveness to sensory stimuli before and after stroke; and the timing of sensory changes.

Responsiveness to sensory stimuli before and after stroke. This category captures participants' description of the difference in their response to sensory stimuli before and after stroke. Participants shared how they reacted to sensory stimuli after stroke. They compared their reaction to light, sound, and touch/vibration to their reaction before the stroke. All participants reported sensitivity to sound/noise after stroke. However, they were not consistent in reporting sensitivity to other sensory stimuli. Some participants did feel the difference in their reaction to the sensation, however they were not able to describe it.

For example, one participant shared "my eyes are sensitive to light and they are watery more than normal before stroke". The same participant also shared "... for some reason the light does bother me more". Another participant shared that she feels differently using power toothbrush after stroke due to sensitivity to touch/vibration 'It's very different now, I don't know how to describe it". The same participant described her sensitivity to loud noises when she is outside "if it is a loud noise and I have no idea that it is gonna happen I just really really jump". She also reflected upon sensitivity to sounds being in a church "there is still so much activity and up and down and noise level and everything I am just not comfortable with that". Regarding 
sensitivity to loud noises as well, another participant mentioned "When I hear a big bang I jump more now, and I didn't use to do that. This is new and different even my husband noticed me".

The timing of the sensory changes. This category focuses on the time that participants started to experience sensitivity after stroke. One participant said "In the beginning of the stroke neither [sensitivity to light or touch] were there). It occurred after, what time frame, I couldn't put my finger on it, but I will say at least anywhere between 1.5-2 years I didn't experience any of these things. So, 2 years after stroke when these sensitivity things came into play". Another participant mentioned "I didn't notice the sensitivity when I was at the hospital, it definitely happened after I left."

Theme two: Impact on participation. This theme addresses the impact of the sensitivity after a stroke on participation in daily life activities and how participants cope with the sensitivity. There are two categories within this theme: Activities that have been impacted, and strategies used to cope with sensory sensitivity.

Impacted activities. The first category within this theme includes the activities that have been affected due to sensitivity after stroke. It also captures participants' feelings toward these changes. All participants reported that sensitivity impacted the activities they participate in (i.e. activities of daily living, social activities and leisure activities). One participant reflected upon the impact of sensitivity to light on his participation in the current interview "I'd rather done this interview in the dark. When I came in in the morning, I set everything up I do it in the dark."

Another participant who played matcha (a board game) shared how sensitivity to sound impacts her participation in the community meetings of the matcha game" we meet once a month and then service activity, but I have not gotten back in to that again because we've got 20 people, and everybody is talking at the same time and trying to pass this or do this...this is too 
much, I am just thinking, I don't know, I don't think I can handle it". The same participant also reported other activities affected "I mean we go to the movies occasionally but that doesn't bother me because you know it is quiet, but in our social group as I said, and even our church is sometimes stressful to go to, and I am always thinking it should be a nice time to be peaceful and meditating”. Although this participant mentioned that social activities were impacted due to sensitivity to sound, she mentioned that she does not have a problem socializing in the community rehabilitation setting (where the interviews took place); she shared 'I don't have problem with that coming here and being with, maybe it is because we are all in the same situation and that is easier for me to relate to with this group of people". As far as the impact of sensitivity on social activities, another participant mentioned “...,I used to watch football games with my husband but now I don't care for them. Another participant shared" I got to situations that I feel this is overwhelming, you know, that's tiring"

Strategies used to cope with sensory changes. The second category within this theme captures strategies participants used to deal with the sensitivity after stroke. Participants reported using different strategies to cope with the sensitivity; avoiding the sensory stimuli that cause the sensitivity, giving up the activity, or finding new ways to complete the activity. One participant shared how she had difficulty processing auditory information from different people "I would say that being in a large group I have trouble with, and so I just avoided it", and she continued "I guess if I get in a situation where I am really uncomfortable, I kind of withdraw and I just try to take in what everybody else is doing or saying and maybe I don't participate like I would have prior to this". She also mentioned the strategy she used to cope with sensitivity to sound "I don't like to go outside when there is a big crowd" Another participant reported "you know I guess I do avoid crowds". Although some participants avoided sensory stimuli that cause sensitivities 
(e.g. noise, light), they did not feel comfortable avoiding activities and preferred to use strategies to cope with their sensitivity. The participant who avoided attending monthly leisure meeting commented 'I don't force myself to do the thing that I am not comfortable with, but that's what I really need to do with the group situation, is I just need to go and get through it, go again and get through it"'.

Another strategy that participants reported using to cope with the sensitivity is modifying the tools to carry out a certain activity. One participant reported "You know without a doubt just having the light dimmer makes me more comfortable". The same person also shared "I wear eyeglasses a lot because of the sensitivity". Another participant shared "I asked my husband to change the lights in the house and make it dimmer". The third participant said "I had the power toothbrush and also the same way with the waterpik. Because of the sensitivity I switched to manual and floss instead of those two items" and she continued "but I cannot get used to it again”.

\section{Discussion}

In this study, we explored the impact of sensory processing patterns on participation in daily life activities among community dwelling stroke survivors. Understanding the relationship between sensory processing patterns and participation in daily life assists health care providers in utilizing individualized care that considers a different aspect of person's life. We explored this relationship through behavioral assessments and a semi-structured interview. Through this process, we came up with two themes and five categories, as well as examined the relationship between sensory patterns and percentage retained of different activities using AASP and ACS.

Based on the analysis between SP and ACS, people with seeking pattern retained a higher percentage of IADLs (e.g. caring for pets, driving, meal preparation and cleanup) and social 
activities. People with seeking patterns integrate active self-regulation strategies that enable them to actively engage and interact with the environment (Engel-Yeger and Rosenblum, 2016). This may explain the relationship between seeking pattern and percentage of retained of IADLs among study participants. Moreover, previous research suggests that people with a seeking pattern were less likely to develop depression (McDonnall, 2009) or social isolation (Saunders \& Echt, 2007) which in turn minimize the risk of participation restriction. Our findings also indicated that the more the person misses sensory cues (i.e. registration pattern), the less the person retains IADLs. Our results were consistent with another study that explored the impact of sensory patterns on occupational engagement among older people (Engel-Yeger and Rosenblum, 2016). The latter study found that among older people, who have seeking pattern retained a higher percentage of IADLs and social activities compared with people who have different patterns. Additionally, the same study found registration pattern to be the best predictor of engagement in IADLs among older adults. Although Engel-Yeger and Rosenblum (2016) studied the general older population, the previous study suggested stroke survivors have similar frequencies of sensory patterns since most of the stoke survivors are older adults ("Exploring Relationships between Fatigue, Motor Changes and Sensory Processing After Stroke", unpublished manuscript).

During the interviews, all three participants conveyed that they have experienced sensitivity to various sensory stimuli (i.e. sound, light, and touch/vibration). Sensitivity to sensory stimuli was not consistent across participants in terms of the type of sensation. All participants reported sensitivity from loud noises; one participant reported sensitivity to vibration, and two participants reported sensitivity to light. Although interview questions didn't focus solely on sensitivity, it was the most salient topic reported by the participants. These 
findings confirmed the findings of a previous qualitative study that people after stroke reported sensitivity to light and sound and it interferes the ability to cope with changes related to everyday life (Carlsson et al., 2009). The current study participants reported that they started to notice the sensitivity to sensory stimuli after about 1-2 years from stroke and they never experienced sensitivity during hospitalization. Stroke survivors confront daily life situations in its real context after they leave the hospital, when they start to experience difficulties and notice factors that inhibit their engagement in daily occupations (Bouffioulx et al., 2011). Another explanation that perhaps people receive more support in the first stage of stroke, and they develop self-reliance later which might change their need to be vigilant of surroundings.

Further, our findings from behavioral assessment data, indicated that sensitivity pattern was correlated negatively with the percentage retained of overall activities (i.e. social, instrumental, and low/high demand leisure activities). Participants confirmed, during the interviews, that sensitivity to sensory stimuli restricted participation in daily life activities (mainly social and leisure activities). These results were in line with the previous literature which suggests that sensitivity to sensory stimuli was the best predictor of reduced participation in daily life activities among older people (Engel-Yeger and Rosenblum, 2016). Perhaps sensitivity to sensory stimuli is not only related to having a stroke but also to being an older adult.

Participants shared that they gave up some social activities due to sensitivity after stroke, however this was not true for all social activities. For example, one participant reported that she felt uncomfortable in large gatherings of family and friends due to sensitivity to noise, however she felt comfortable socializing at the community rehabilitation setting. This participant mentioned that she can relate to the latter group more than to her family since they share the same circumstances. On one hand, this could be an indication of the importance of the 
community settings programs to encourage stroke survivors to socialize with other people who share the same experiences. On the other hand, it confirms the findings from the literature that stroke survivors play an "active and creative role" in managing participation in daily life activities after stroke (Pound, Gompertz, \& Ebrahim, 1999).

Participants mentioned different strategies to manage engagement in daily life activities and cope with sensitivity after stroke. One of these strategies is creating new ways to carry out certain activities; for example, one of the participants mentioned using the manual toothbrush instead of the power toothbrush to avoid the sensitivity to vibration. Interestingly, a previous study also mentioned some people after stroke preferred using a manual toothbrush over a power toothbrush (Wu, Branson, \& Alwawi, 2016). Our findings, from behavioral assessments, indicated a moderate relationship, yet not significant, between the avoiding sensory processing pattern and the percentage retained of overall activities. That is, the participant with a higher tendency to avoid sensations participated in fewer daily activities. The qualitative data confirmed this relationship - people who reported sensitivity to sensory stimuli actively avoided participating in certain social and leisure activities. Furthermore, these results are in line with the Engel-Yeger and Rosenblum (2016) study that found older adults who have avoiding pattern were less likely to participate in social activities.

Although people describe sensitivity to sensory stimuli, they showed similar frequency of sensitivity pattern when compared to the norming sample. One participant showed a higher frequency in registration pattern. Previous research suggests people experience changes after stroke which are rarely to be addressed by health care professionals (Carlsson, Möller, \& Blomstrand, 2004). However, it impacts participation in daily life activities. One of these changes is missing some sensory events after stroke (e.g. leaving the cabinet open, or the water 
running). Authors mentioned that this dysfunction is not understood by the person or his/her family. Based on the results of our study, perhaps leaving the water running is an indication that this person has registration pattern (i.e. miss more input). This current study explored a new factor that might affect engagement in daily activities among stroke survivors and invites health care provider to consider sensory patterns as an invaluable factor to understand client's behaviors.

\section{Limitations}

This study was conducted on a small sample size, so the results may not generalize to a larger stroke population. However, we used non-parametric statistics to examine the correlations. Future research might consider a larger and more diverse sample size. Given the complexity of the factors that might affect person's functional performance, it was hard to control all the factors affecting person's engagement in daily activities (e.g., executive functions, physical changes, psychological and emotional factors). Although study results showed the relationship between sensory patterns and participation in daily activities, we acknowledge that there are other factors impact person's engagement and sensory patterns only one of these factors. By integrating the results from the AASP with the results of the other assessments, and observation we can capture a better and more accurate picture of person's participation in daily activities. Regarding the qualitative data, we conducted these interviews to test the feasibility of the interview questions to be used in a study with larger sample size. 


\section{Conclusion}

It is important to understand the factors impact participation in everyday life activities among stroke survivors. The study findings indicated that sensory processing patterns may impact engagement in daily activities (i.e. social, leisure, and IADLs) among people who have experienced a stroke. Given these results, health professionals would create interventions fit person's need to improve participation and quality of life. Understanding the relationship between sensory patterns and participation could also encourage health professionals to consider the person's real-life environment and understand what sensory modalities facilitate or inhibit engagement in their occupations. Improving family awareness of sensory patterns and its impact on participation among stroke survivors may help professionals find the best environmental modifications that match the person's sensory needs. Interestingly, the current study findings were in line with the previous study findings regarding the impact of sensory patterns on occupational engagement among older adults (Engel-Yeger and Rosenblum, 2016). This may invite health professionals to keep in mind that some of the changes a stroke population exhibits are part of being older adults who also exhibit changes with aging. 


\section{References}

American Occupational Therapy Association. (2014). Occupational therapy practice framework: Domain and process. American Journal of Occupational Therapy, 68, S1-S48. doi:10.5014/ajot.2014.682006

Baum, C.M., \& Edwards, D. F. (2001). The Activity Card Sort. St Louis, MO: Washington University School of Medicine

Bouffioulx, É., Arnould, C., \& Thonnard, J. L. (2011). Satisfaction with activity and participation and its relationships with body functions, activities, or environmental factors in stroke patients. Archives of physical medicine and rehabilitation, 92(9), 1404-1410. doi: 0.1016/j.apmr.2011.03.031

Brown, C., \& Dunn, W. (2002). The Adolescent/Adult Sensory Profile: User's manual. San Antonio, TX: The Psychological Corporation.

Brown, C., Tollefson, N., Dunn, W., Cromwell, R., \& Filion, D. (2001). The Adult Sensory Profile: Measuring patterns of sensory processing. American Journal of Occupational Therapy, 55,75-82.

Carlsson, G., Möller, A., \& Blomstrand, C. (2004). A qualitative study of the consequences of 'hidden dysfunctions' one year after a mild stroke in persons $<75$ years. Disability and rehabilitation, 26(23), 1373-1380. doi: 10.1080/09638280400000211

Carlsson, G. E., Möller, A., \& Blomstrand, C. (2009). Managing an everyday life of uncertaintya qualitative study of coping in persons with mild stroke. Disability and rehabilitation, 31(10), 773-782. doi: 10.1080/09638280802638857 
Cawood, J., Visagie, S., \& Mji, G. (2016). Impact of post-stroke impairments on activities and participation as experienced by stroke survivors in a Western Cape setting. South African Journal of Occupational Therapy, 46(2), 10-15. doi:10.17159/2310-3833/2016/v46n2a3

Chan, V. W., Chung, J. C., \& Packer, T. L. (2006). Validity and reliability of the Activity Card Sort_Hong Kong version. OTJR: Occupation, Participation and Health, 26(4), 152-158.

Chung, S. M., \& Song, B. K. (2016). Evaluation of sensory processing abilities following stroke using the adolescent/adult sensory profile: Implications for individualized intervention. Journal of Physical Therapy Science, 28(10), 2852-2856.

Connell, L. A., McMahon, N. E., \& Adams, N. (2014). Stroke survivors' experiences of somatosensory impairment after stroke: An Interpretative Phenomenological Analysis. Physiotherapy, 100(2), 150-155. doi:10.1016/j.physio.2013.09.003

Cunningham N, Rhoda, R. (2014). Outcomes of stroke patients discharged from an in-patient facility in the Eastern Cape, South Africa: A mixed methods design. South African Journal of Physiotherapy, 70(3): 26-31.

Doyle, S. D., Bennett, S., \& Dudgeon, B. (2014). Upper limb post-stroke sensory impairments: the survivor's experience. Disability and rehabilitation, 36(12), 993-1000. doi: $10.3109 / 09638288.2013 .825649$

Engel-Yeger, B., \& Rosenblum, S. (2017). The relationship between sensory-processing patterns and occupational engagement among older persons. Canadian Journal of Occupational Therapy, 84 (1). doi:10.1177/0008417417690415.

Hartman-Maeir, A., Soroker, N., Ring, H., Avni, N., \& Katz, N. (2007). Activities, participation and satisfaction one-year post stroke. Disability and rehabilitation, 29(7), 559-566. doi: $10.1080 / 09638280600924996$ 
McDonnall, M. C. (2009). Risk factors for depression among older adults with dual sensory loss. Aging and Mental Health, 13, 569-576. doi:10.1080/13607860902774410

Meyer, S., Karttunen, A. H., Thijs, V., Feys, H., \& Verheyden, G. (2014). How do somatosensory deficits in the arm and hand relate to upper limb impairment, activity, and participation problems after stroke? A systematic review. Physical therapy, 94(9), 12201231. https://doi.org/10.2522/ptj.20130271

Pohl, P. S., Dunn, W., \& Brown, C. (2003). The role of sensory processing in the everyday lives of older adults. OTJR: Occupation, Participation and Health, 23(3), 99-106.

Pound, P., Gompertz, P., \& Ebrahim, S. (1999). Social and practical strategies described by people living at home with stroke. Health \& social care in the community, 7(2), 120-128. doi: 10.1046/j.1365-2524.1999.00168.x

Rhoda, A. (2012). Limitations in activity and participation experienced by stroke patients: A qualitative inquiry. South African Journal of Physiotherapy, 68(3), 20-24. doi: 10.4102/sajp.v68i3.20.

Saunders, G. H., \& Echt, K. V. (2007). An overview of dual sensory impairment in older adults: perspectives for rehabilitation. Trends in Amplification, 11, 243-258. doi:10.1177/108471 3807308365

World Health Organization. (2001). International classification of functioning, disability and health: ICF. Geneva, Switzerland: Author.

Wu, A. J., Branson, B., \& Alwawi, D. (2016) Toothbrushing ability after left stroke. Poster session presented at the American Occupational Therapy Association Annual Conference \& Expo, Chicago, IL. 
Table 1

Demographic Information

\begin{tabular}{|c|c|c|c|c|c|c|}
\hline Participant & Age & Gender & $\begin{array}{l}\text { Marital } \\
\text { Status }\end{array}$ & Previous Occupation & $\begin{array}{l}\text { Side of } \\
\text { Stroke }\end{array}$ & $\begin{array}{l}\text { Type of } \\
\text { Stroke }\end{array}$ \\
\hline 1 & 65 & Male & Divorced & Architect & Left & Ischemic \\
\hline 2 & 63 & Male & Married & Accountant & Right & Hemorrhagic \\
\hline 3 & 64 & Female & Married & $\begin{array}{l}\text { Administrative assistant } \\
\text { for a company }\end{array}$ & Left & Ischemic \\
\hline 4 & 51 & Female & Single & Stylist & Right & Hemorrhagic \\
\hline $5 *$ & 74 & Female & Married & $\begin{array}{l}\text { Cashier at Hallmark } \\
\text { Cards }\end{array}$ & Left & Hemorrhagic \\
\hline $6^{*}$ & 64 & Male & Single & Manager of car wash & Left & Ischemic \\
\hline $7 *$ & 65 & Female & Married & Housewife & Right & Ischemic \\
\hline 8 & 63 & Male & Single & Cargo handler & Right & Ischemic \\
\hline
\end{tabular}

Note. ${ }^{*}$ Indicates the participant completed both the interview and the behavioural assessments 
Table 2

Correlation between the Percentages retained of Activities (according to Activity Card Sort; ACS) and Sensory Patterns

\begin{tabular}{|c|c|c|c|c|}
\hline Activity type according to ACS & $\begin{array}{c}\text { Registration } \\
r_{s}(p)\end{array}$ & $\begin{array}{c}\text { Seeking } \\
r_{s}(p)\end{array}$ & $\begin{array}{c}\text { Sensitivity } \\
r_{s}(p)\end{array}$ & $\begin{array}{c}\text { Avoiding } \\
r_{s}(p)\end{array}$ \\
\hline Instrumental Activities & $-.71^{*}(.05)$ & $.90^{* *}(.002)$ & $-.53(.19)$ & $-.42(.30)$ \\
\hline Low demand Leisure Activities & $-.18(.67)$ & $.42(.307)$ & $-.29(.50)$ & $-.42(.307)$ \\
\hline High demand Leisure Activities & $-.17(.70)$ & $.59(.13)$ & $-.74^{*}(.04)$ & $-.47(.25)$ \\
\hline Social Activities & $-.44(.27)$ & $.66(.07)$ & $-.64(.08)$ & $-.59(.13)$ \\
\hline Global Activities retained & $-.59(.13)$ & $.56(.15)$ & $-.76^{*}(.03)$ & $-.61(.11)$ \\
\hline
\end{tabular}


Table 3

Themes and Categories with Examples of Participant Quotes

\begin{tabular}{|c|c|c|}
\hline Themes & Categories & Sample of Quotes \\
\hline \multirow[t]{4}{*}{$\begin{array}{l}\text { 1. What does sensitivity feel } \\
\text { like? }\end{array}$} & $\begin{array}{l}\text { 1a: Responsiveness to sensory } \\
\text { stimuli before and after stroke }\end{array}$ & $\begin{array}{l}\text { "and even before stroke, I } \\
\text { want to be correct, } \\
\text { thorough, and complete." }\end{array}$ \\
\hline & & $\begin{array}{l}\text { "my eyes are sensitive to } \\
\text { light and they are watery } \\
\text { more than normal before } \\
\text { stroke" }\end{array}$ \\
\hline & 1b: Timing of the sensitivity & $\begin{array}{l}\text { "I didn't notice the } \\
\text { sensitivity when I was at } \\
\text { the hospital, it definitely } \\
\text { happened after I left." }\end{array}$ \\
\hline & & $\begin{array}{l}\text { "...but I will say at least } \\
\text { anywhere between } 1.5-2 \\
\text { years..." }\end{array}$ \\
\hline \multirow[t]{4}{*}{$\begin{array}{l}\text { 2. What happens because of the } \\
\text { sensitivity? }\end{array}$} & 2a: Impacted activities & $\begin{array}{l}\text { "I used to watch football } \\
\text { games with my husband } \\
\text { but now I don't care for } \\
\text { them." }\end{array}$ \\
\hline & & $\begin{array}{l}\text { "I mean we go to the } \\
\text { movies occasionally but } \\
\text { that doesn't bother me } \\
\text { because you know it is } \\
\text { quiet..." }\end{array}$ \\
\hline & $\begin{array}{l}\text { 2b: Strategies used to cope } \\
\text { with sensory sensitivity }\end{array}$ & $\begin{array}{l}\text { "I guess if I get in a } \\
\text { situation where I am } \\
\text { really uncomfortable, I } \\
\text { kind of withdraw" }\end{array}$ \\
\hline & & $\begin{array}{l}\text { "You know without a } \\
\text { doubt just having the light } \\
\text { dimmer makes me more } \\
\text { comfortable" }\end{array}$ \\
\hline
\end{tabular}

